\title{
CONDITION MONITORING OF SLOW-SPEED ROLLING ELEMENT BEARINGS USING STRESS WAVES
}

\author{
N. Jamaludin ${ }^{1}$, B.Sc, Msc, D. Mba ${ }^{1}$, B.Eng, PhD and R.H. Bannister ${ }^{1}$, B.Sc, Msc, PhD. \\ ${ }^{1}$ School of Mechanical Engineering, Cranfield University, Cranfield, Beds. MK43 0AL.
}

Synopsis- Condition monitoring of rolling element bearings through the use of vibration analysis is an established technique for detecting early stages of component degradation. However, this success has not mirrored at rotational speeds below $16 \mathrm{rpm}$. At such speeds the energy generated from bearing defects might not show as an obvious change in signature and thus become undetectable using conventional vibration measuring equipment.

This paper presents an investigation into the applicability of stress wave analysis for detecting early stages of bearing damage at a rotational speed of $1.12 \mathrm{rpm}(0.0187 \mathrm{~Hz})$. Furthermore, it reviews work undertaken in monitoring bearings rotating at speeds below $16 \mathrm{rpm}$.

Key words- Auto-regressive coefficients, dendrograms, K-means clustering, slow-speed rotating machinery, stress waves. 


\section{Introduction}

This research originated from difficulties with low-speed ( 0.6 to $1.2 \mathrm{rpm}$ ) rolling element bearings used in the UK water industry $(1,2,3)$. Types of damage listed included cage fracture, scoring of shafts and bearing housings, severe roller wear and grease contamination. However, due to the nature of their investigation (2), these defects were at an advanced stage and easily detected. Investigating the applicability of Stress wave analysis to all the defects detailed above is beyond the scope of this paper; however, it presents investigations on the early stages of surface degradation and grease contamination.

Mba et. al. (3) attributed bearing failures in their studies to be due to the application of grease with an inappropriate base oil viscosity. With several hundred bearings in operation the cost of grease removal and replacement is considerably high. Although there is a gradual replacement programme in place, there is also a need for a monitoring system that can be utilised for early fault detection, regardless of the type of grease employed. For this reason the presented research investigated monitoring early defects on bearings operating in two types of grease. The first, type A, was a standard grease used for medium to high speed bearings (base oil viscosity $180 \mathrm{~mm}^{2} / \mathrm{s}$ at $40^{\circ} \mathrm{C}$ ), while the second, type $\mathrm{B}$, consisted of a base oil viscosity of $1000 \mathrm{~mm}^{2} / \mathrm{s}$ at $40^{\circ} \mathrm{C}$, appropriate for the rotational speed of investigation $(<2 \mathrm{rpm})$. 


\section{Limitations of vibration analysis at low rotational speeds}

Monitoring bearing degradation by vibration analysis is an established technique and the various methods of analysis have been widely published $(4,5,6,7,8,9)$. However, at lowrotation speeds there are numerous difficulties which have been detailed $(10,11,12)$. The main problems can be divided into four sections :

1. Optimum measurement parameter for low-frequency vibration: Conventional vibration systems employ accelerometers, though displacement sensors are best suited to low speed frequency analysis.

2. Instrument limitations for low-frequency analysis: Involves overcoming inherent lowfrequency instrument noise problems, and, low-frequency roll-off limitations of the charge amplifier.

3. Sensor requirements for low frequency analysis: Most sensors have roll-off filters that affect the magnitude of signals detected within the roll-off frequency range.

4. Coupling between the sensor and the data collector: Murphy (12) suggested that a strong magnetic clamp be used to attach the sensor to the machine, thus avoiding the rocking effects as would be experienced with a hand held probe, thereby reducing unwanted noise at very low frequencies. Others $(11,13)$ suggest the use of a coaxial cable to minimise any electrical noise pickup, and, to avoid hanging cables to eliminate tribo-electric effects at low frequencies. 


\section{Review of monitoring techniques applied to bearings rotating at less than}

16 rpm.

The four points highlighted in the previous section make vibration monitoring of lowspeed rotating machinery almost impossible, though some attempts have been made. Kuboyama (14) summarised the difficulty with monitoring low speed rotating machinery, by stating that "At over $100 \mathrm{rpm}$, it is easy to diagnose the condition of degradation and damage using vibration analysis. This is because vibrations have a great amount of energy and occur over a short period. On the other hand, with a rotating machine working at less than $100 \mathrm{rpm}$, it is difficult to diagnose damage or degradation because of the small amount of energy and the vibrations occur over a longer period". Several techniques for monitoring low-speed bearings were suggested (14), particularly, the Peak Level Differential method. This technique was applied to rolling element bearings of the same type and size. Noise was rejected by band pass filtering of the bearings natural frequencies.

Acceleration peaks exceeding pre-set threshold levels were held by what Kuboyama (14) referred to as a "peak picker". The peak level differentials between both bearings and the number of occurrences were calculated, when values exceeded a certain criteria the bearing was judged to have sustained damage. This technique required the comparison of two bearings and was applied to pinch roller bearings that were operated at $1 \mathrm{rpm}$. Successful detection of flaking on the surface of the inner race on one of the bearings was 
claimed, however, Kuboyama (14) does not specify the type of measuring equipment, nor characteristics of the sensor used.

Canada et. al. (11) developed a Slow Speed Technology (SST) system for measuring vibrations on low-speed machinery. It was based on separating the high frequency noise of the machine from the low frequency signatures of interest. This was accomplished with an analog integrator. It was stated that although analog integrators distort the low frequency components, this distortion is deterministic, hence the effect can be corrected. The method was shown to give improved performance when compared to digital integration and was applied to a variable low-speed rotor unit with an adjustable cam rotating at between 15 to $150 \mathrm{rpm}$. Claims that this method could be applied at speeds as low as $10 \mathrm{rpm}$ were made.

Robinson et. al (13) proposed a new methodology for vibration monitoring of low speed machinery. This built on the SST method described earlier (Canada et. al. [11]). It involved segmenting the signal into time intervals, dependent on the sampling frequency, and obtaining peak values for continuing time intervals until the desired number are captured for processing. Processing peak values involved spectral analysis. Field measurements using low-frequency accelerometers on bearings rotating at $10 \mathrm{rpm}$ showed that the peak value technique detected inner race defects one month prior to failure. 
More relevant to this paper is the research on acoustic emission (AE) and its applicability for monitoring low-speed bearings. Sato (15) investigated the use of AE to monitor lowspeed bearing damage by simulating metal wipe in journal bearings at $5.5 \mathrm{rpm}$. It was observed that acoustic bursts were generated as a result of slight metallic contact and the amplitude of the waveform became larger with increasing metal wear.

McFadden et. al. (16) explored the use of acoustic emission transducers for the monitoring of rolling element (angular contact) bearings at speeds varying from 10 to $1850 \mathrm{rpm}$. The sensors were placed on the bearing housing. A fault, simulated by a fine scratch on the inner raceway, formed the basis of this experiment. At low rotational speeds $(10 \mathrm{rpm})$ the $\mathrm{AE}$ transducer appeared to respond to minute strains (local distortions) of the bearing housing caused by the concentrated loading of each ball in the bearing. These minute strains appeared as spurious spikes superimposed on the ball pass frequency. Measurements with conventional strain gauges failed to detect the strain on the bearing housing. The ball pass frequency was detected with a fault signature superimposed onto the original signal in the time domain.

McFadden (16) concluded that at low speeds with steady loads, base bending/strain of the bearing housing could enable the AE transducer to detect signatures from very small defects in rolling element bearings, while at higher speeds base bending appears as low frequency noise. 
Smith (17) was involved in the experiment mentioned above and in a separate paper reiterated McFadden's (16) findings though puzzled at the behaviour of the AE sensor used, stating " the form of response of the AE sensor was puzzling since the transducer was responding to once-per-ball distorting in the casing at frequencies as low as $1 \mathrm{~Hz} . \mathrm{AE}$ transducers are not supposed to respond to frequencies as low as these".

It is apparent that condition monitoring of low-speed machinery using vibration analysis and acoustic emissions is fraught with difficulties and there are limited claims of success. Only one paper was directly relevant to this research $(1 \mathrm{rpm})$, unfortunately the author (Kuboyama [14]) failed to specify the equipment used for detection.

\section{Suitability of stress waves (SW) as a monitoring tool.}

Stress waves are defined as the transient waves generated by the interaction of two surfaces that are in relative movement. In this instance, rubbing between metal surfaces in contact. The formation, deformation, and fracture of surface irregularities or asperities, which is associated with friction of metals (13), and the motion of entrapped wear debris causing ploughing, will result in the generation of stress waves. This makes it an ideal tool for application to condition monitoring of slow-speed rotating rolling element bearings. 


\section{Test-rig and measuring equipment}

A test-rig was designed to simulate early stages of bearing defects. The rig consisted of a motor/gearbox system, two support slave bearings, a test bearing and a hydraulic cylinder ram, see figure 1 . The test bearing was a split Cooper spherical roller. This type of bearing was chosen due to its ability to be disassembled without removing the slave bearings, thereby allowing the test bearing to be regularly inspected throughout the test programme. The technical specifications of the test bearing are shown in table 1 . The support bearings were of a much larger size than the test bearing. These were type SKF 22222EK, with an internal (bore) diameter of $100 \mathrm{~mm}$.

\section{Table 1 Split cooper bearing technical specifications}

\begin{tabular}{|l|l|}
\hline Bearing type: & Split Cooper bearing Series 01B65 EX \\
\hline Internal (bore) diameter, d: & $65 \mathrm{~mm}$ \\
\hline External diameter, D: & $114.30 \mathrm{~mm}$ \\
\hline Static load rating, $\mathbf{L}_{\mathbf{S}}$ & $110 \mathrm{kN}$ \\
\hline Length of the roller, l: & $19.05 \mathrm{~mm}$ \\
\hline Diameter of the roller, rd: & $14.287 \mathrm{~mm}$ \\
\hline Number of rollers, $\mathbf{Z}:$ & 12 \\
\hline
\end{tabular}




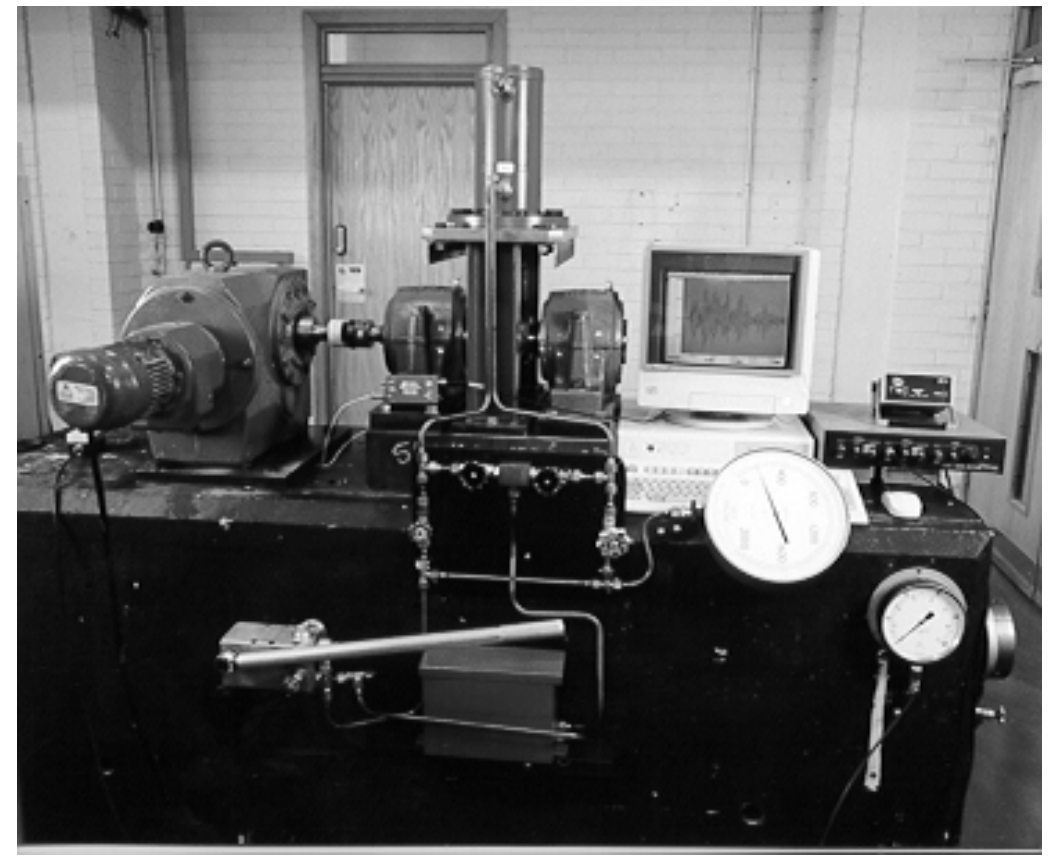

Figure $1 \quad$ Bearing test-rig

The motor/gear box system used was a KA96R62 Helical-Bevel geared motor, providing a rotational speed of $1.12 \mathrm{rev} / \mathrm{min}$. A radial load was applied to the top of the test bearing via a hydraulic cylinder ram supported by a ' $\mathrm{H}$ ' frame. A constant load of 55.00KN was applied to the test bearing for all the experimental tests, providing a safety factor of 2 .

The process of data acquisition involved fixing a receiving transducer onto the test bearing, amplification and digitising of measured signatures, and signal processing. A schematic diagram illustrating the data acquisition system used throughout all experimental tests is shown in figure 2. A commercially available piezoelectric type sensor (Physical Acoustics Corporation type WD) with an operating frequency range between $100 \mathrm{kHz}$ and $1000 \mathrm{kHz}$ at temperatures ranging from -65 to $177^{\circ} \mathrm{C}$, was used. The pre-amplifier used on all experimental tests was a PAC (Physical Acoustics 
Corporation) type $1220 \mathrm{~A}$, specially designed for $\mathrm{AE}$ measurements, having a bandwidth of between $20 \mathrm{kHz}$ and $1.2 \mathrm{MHz}$, at $20 \mathrm{~V}$ peak to peak. The pre-amplifier had a noise specification of less than $2 \mu \mathrm{V}$ plus a switch-able gain of $40-60 \mathrm{~dB}$. A dual-channel 8-bit analogue-to-digital converter (ADC) Rapid Systems R2000 was used for data acquisition. The system provided sampling rates of between $1 \mathrm{~Hz}$ and $20 \mathrm{MHz}, 128 \mathrm{~Kb}$ memory capability per channel, 100 per cent pre-and post-trigger capability and a selectable gain range of between 0.256 and $1280 \mathrm{~V}$. The electronic noise level on the ADC system, with $60 \mathrm{~dB}$ amplification, had a peak voltage of $30 \mathrm{mV}$.

The measurement transducer was cemented to the top of the test bearing housing to obtain uniform force and consistent measurements throughout the experimental tests. The sampling rate employed for all tests was $5 \mathrm{MHz}$. During the experiments, stress wave (SW) signatures were initially obtained from a good bearing to provide baseline, or background noise data. Stress wave signatures for each simulated fault condition were recorded for several revolutions of the shaft until 30 data sets were obtained. 


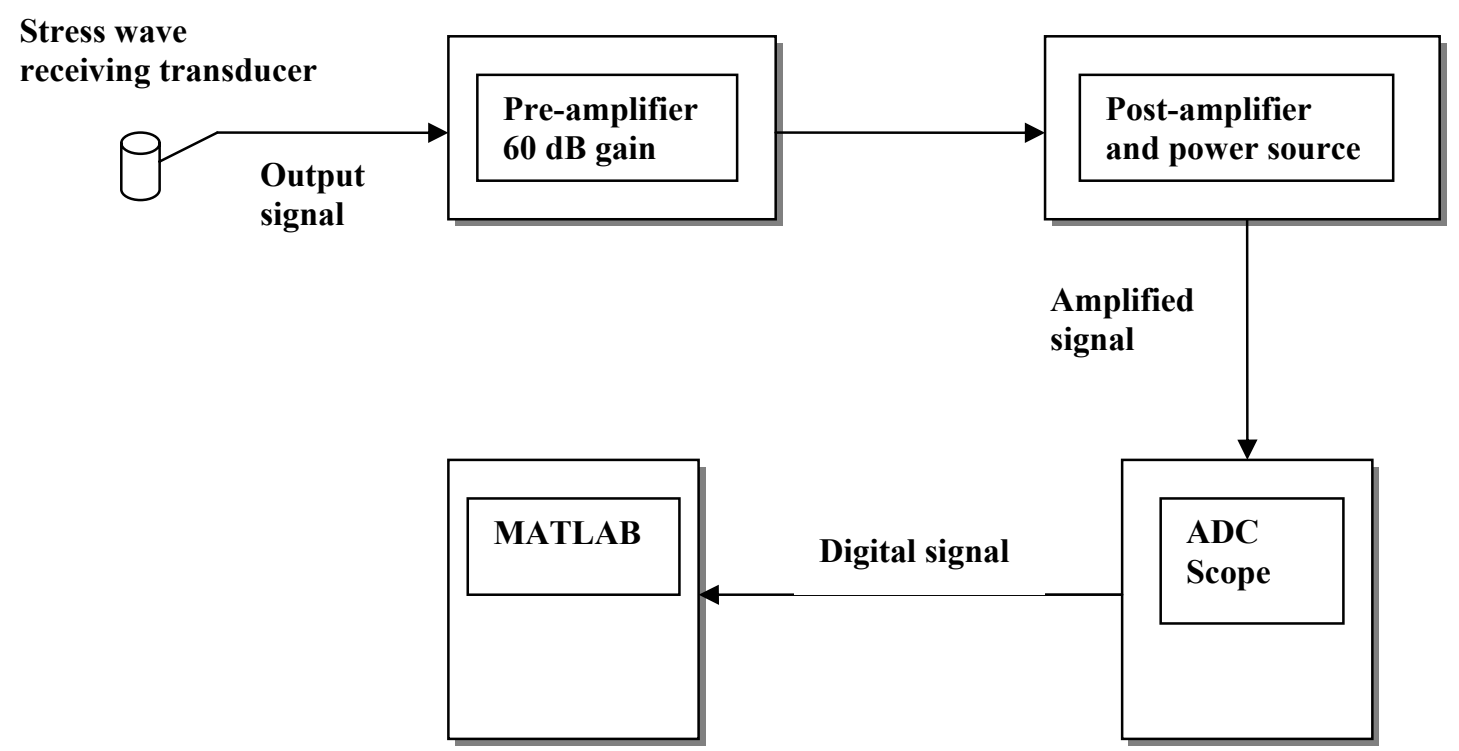

Figure 2 Schematic diagram of data acquisition system

\section{Experimental procedure}

Attempts had been made to generate a natural defect onto the bearing components by fatiguing. However, after allowing the test bearing to operate for a period of 800 hours whilst under conditions of grease starvation, no defect and/or wear was visually detectable on any of the bearing components. This was attributed to the low speed phenomena of $1 \mathrm{rpm}$ and lack of contaminants to initiate and accelerate defect. Since fatigue testing was unable to create any natural defect on the bearing components, seeded surface defects were introduced. These included:

6.1 A uniform surface line defect manufactured on the outer race, inner race and rolling element using an Electro Discharge Machine (EDM) (18, 19, $20,21)$. This defect was intended to simulate early stages of surface 
degradation. The nominal width and depth of the line defect on each component was measured at $0.5100 \mathrm{~mm}$ and $0.7500 \mathrm{~mm}$ respectively, and these measurements were undertaken with a Laser Form Talysurf machine.

6.2 Localised surface defects were also seeded on bearing components using the spark erosion technique $(22,23,24$, and 25$)$. This involved inscribing a defect across the full width of the working surface, and, resulted in surface damage that resembled pitting. This was intended to simulate a surface defect that had progressively worsened, in this instance, from the EDM defect. The defect size on each component was approximately $3.0 \mathrm{~mm}$ wide and an effective depth of $75 \mu \mathrm{m}$.

6.3 Finally, introducing debris particles into the test bearing simulated grease contamination. The debris particles were obtained from cast steel S230 shot peening materials with a nominal diameter of $0.230 \mathrm{~mm}$.

For all three simulated cases detailed above, stress wave signatures were collected for two types of grease, A and B. Grease A is a general application grease while grease B is formulated specifically for a slow-speed rotating machinery. Properties of these grease types are shown in Table 2. Tests were undertaken while the housing of the test bearing was completely filled with grease. Weighing the grease to ensure repeatability throughout the tests identified the filling capacity of the test bearing. 
Table 2 Properties of the lubricants used in the study

\begin{tabular}{|c|c|c|c|}
\hline Lubricant & $\begin{array}{c}\text { Kinematic viscosity, } \\
\mathbf{m m}^{\mathbf{2}} / \mathbf{s} \text { at } \mathbf{4 0}\end{array}$ & $\begin{array}{c}\text { Pressure exponent of } \\
\text { viscosity, } \\
\end{array}$ & $\begin{array}{c}\mathbf{1 0}^{-9} \mathbf{m}^{\mathbf{2}} / \mathbf{N} \\
\mathbf{~ k g} / \mathbf{m}^{\mathbf{3}}\end{array}$ \\
\hline Grease A & 180 & 25 & 880 \\
\hline Grease B & 1000 & 25 & 880 \\
\hline
\end{tabular}

\section{Experimental results}

The method of data measurement involved setting a trigger level above the electronic noise level of the data acquisition system. This noise level peaked at $30 \mathrm{mV}$ and was determined by settings on the acquisition system and pre-amplifier (60dB).

\subsection{Operational baseline measurements}

To obtain operational background noise, the test-rig was run without any seeded fault on the bearing, for the two grease types. Continuos data was recorded with a pre-trigger level set above $30 \mathrm{mV}$. A typical signature with a corresponding frequency spectrum can be seen in figure 3. Observations and analysis showed that the maximum amplitude for this condition did not exceed $170 \mathrm{mV}$. Therefore, on tests with seeded defects the pretrigger level was set slightly above $170 \mathrm{mV}$ in order that SW's associated with defects could be measured. 

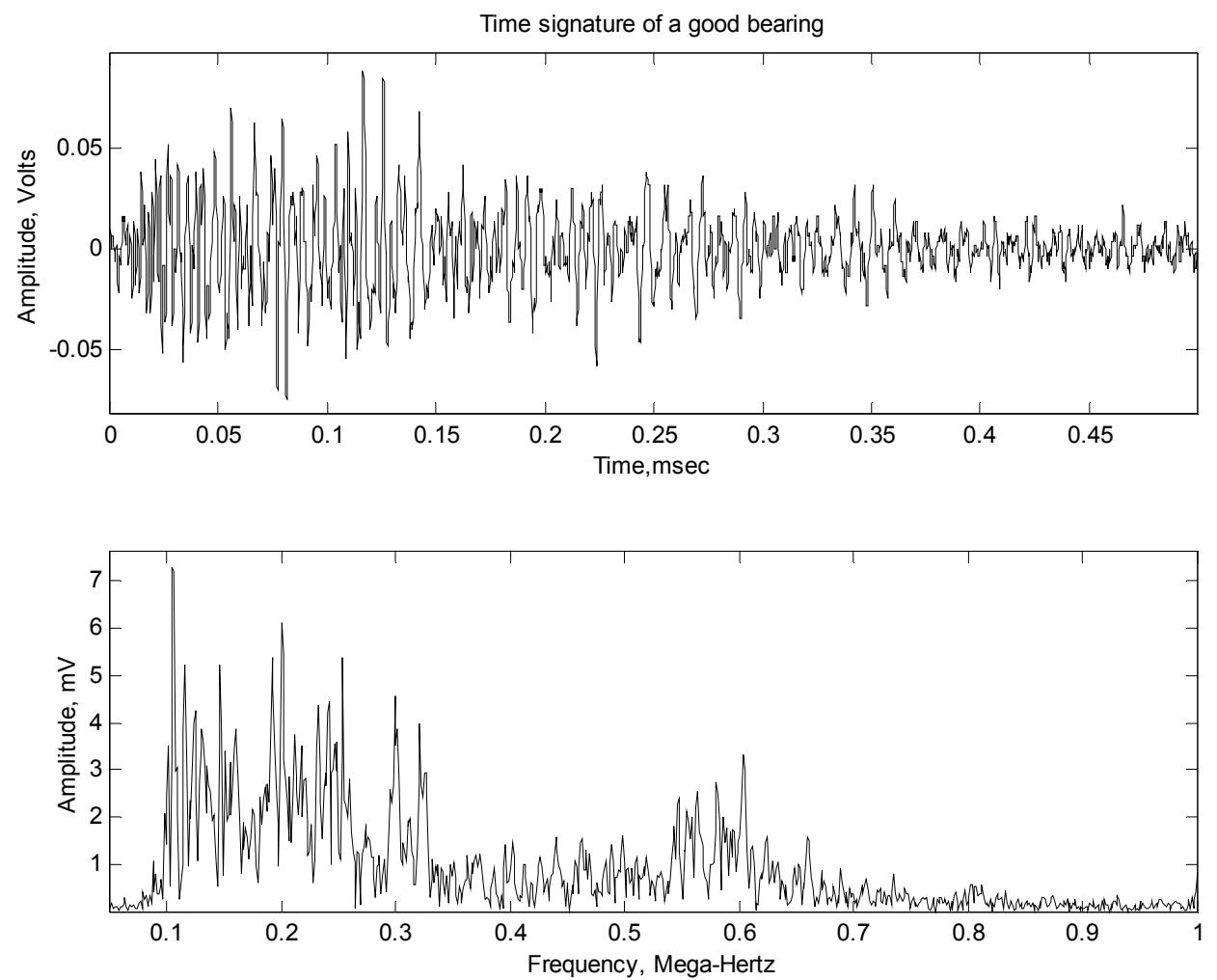

Figure 3 Typical time signature with corresponding frequency spectrum for a good bearing

\subsection{Seeded fault simulation}

\subsubsection{Electro Discharge Machined defects}

No SW signatures were detectable for faults seeded by this technique, i.e., no SW's were detected above the operation baseline trigger level. 


\subsubsection{Spark Erosion}

Faults seeded with this technique resulted in stress wave activity above the operation baseline trigger level. The signatures were correlated to the fault condition by monitoring the position of bearing components at the time of acquisition, i.e., signatures were generated only when the seeded fault was within the loaded region of the bearing. Typical SW signatures for the various defect conditions, with corresponding frequency spectra, are displayed in figures 4 to 6 . The SW's showed their duration to be no more than $1 \mathrm{msec}$, equivalent to 5000 data points at a sampling rate of $5 \mathrm{MHz}$.
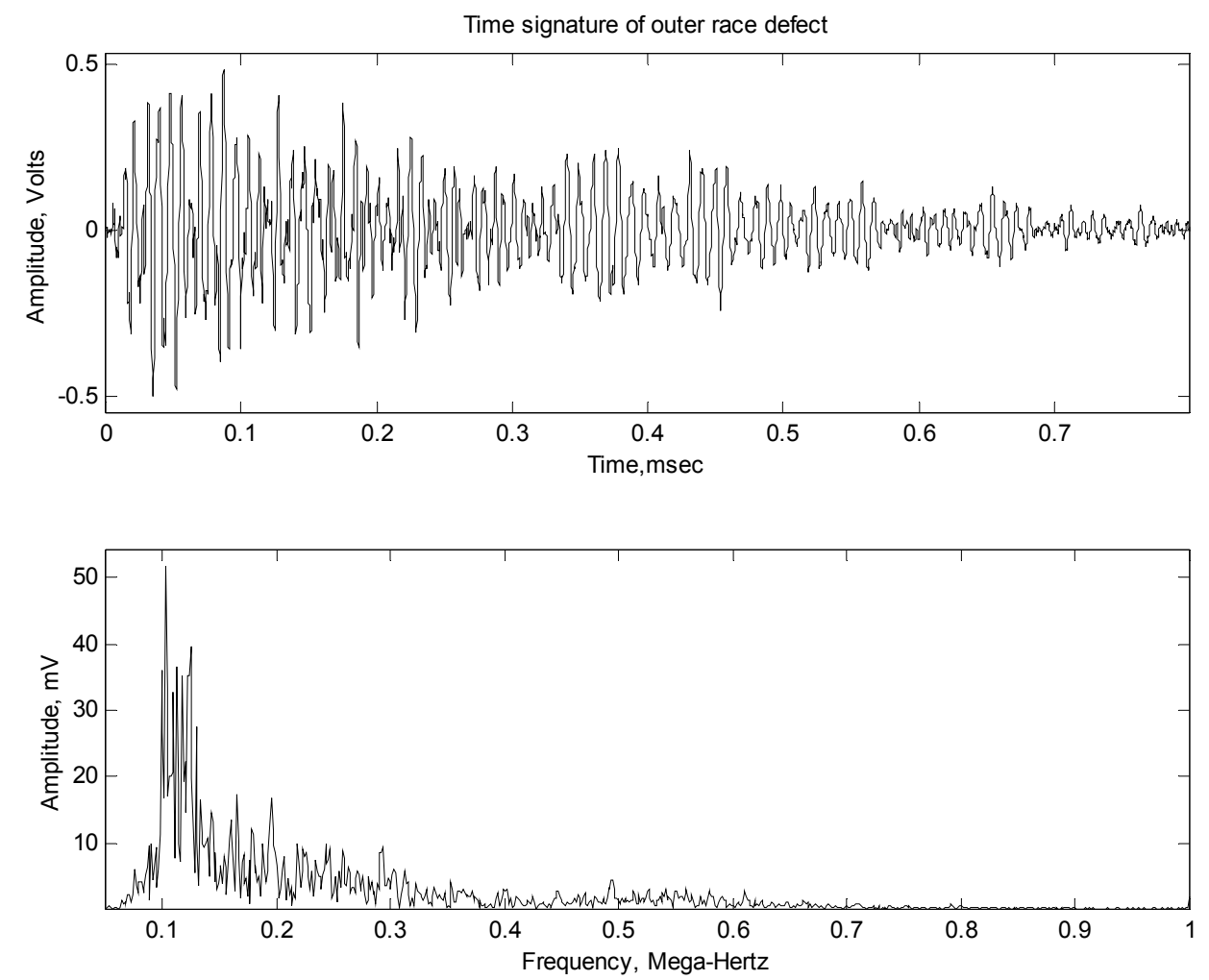

Figure 4 Typical time signature with a corresponding frequency spectrum, outer race defect 

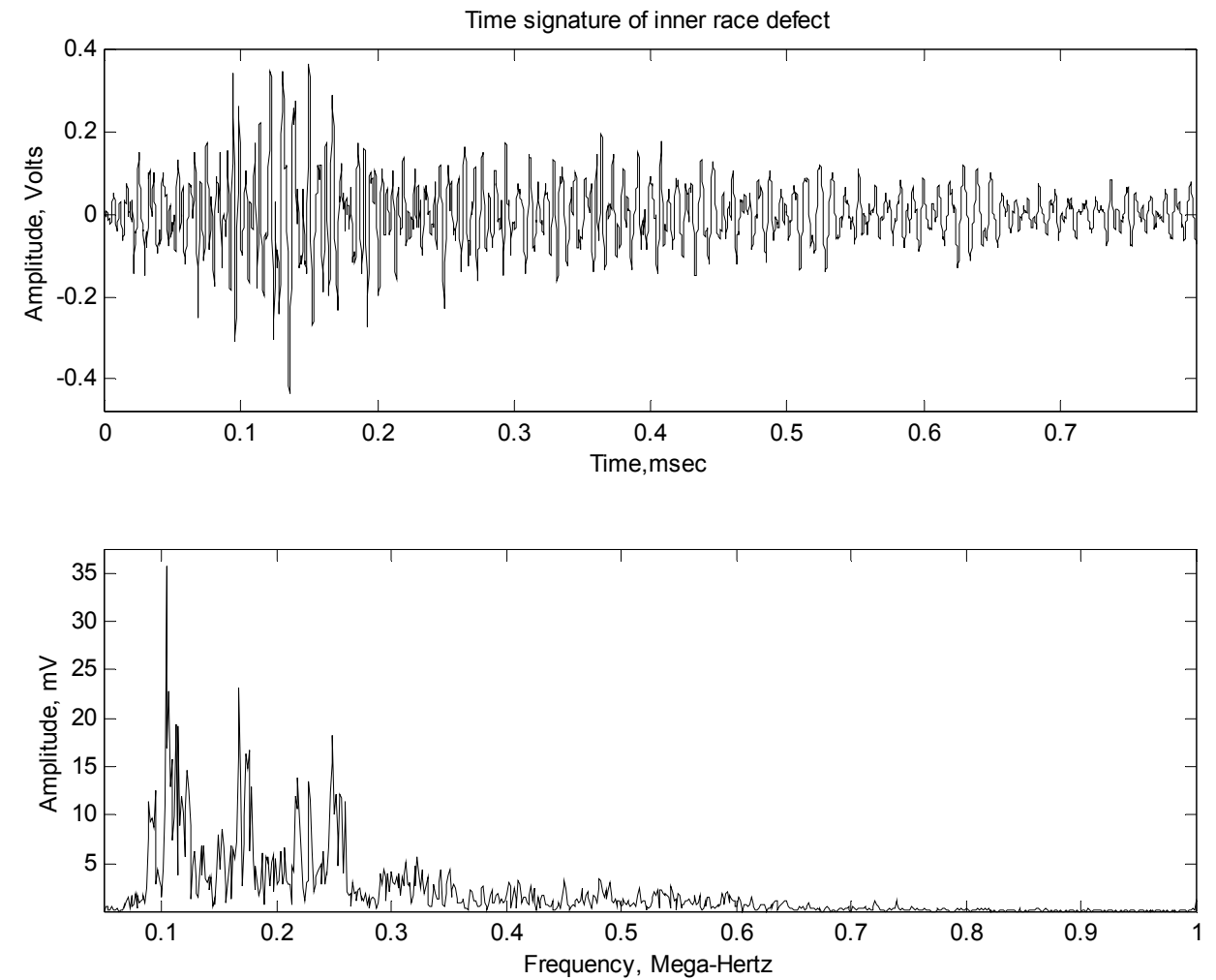

Figure 5 Typical time signature with corresponding frequency spectrum, inner race defect. 

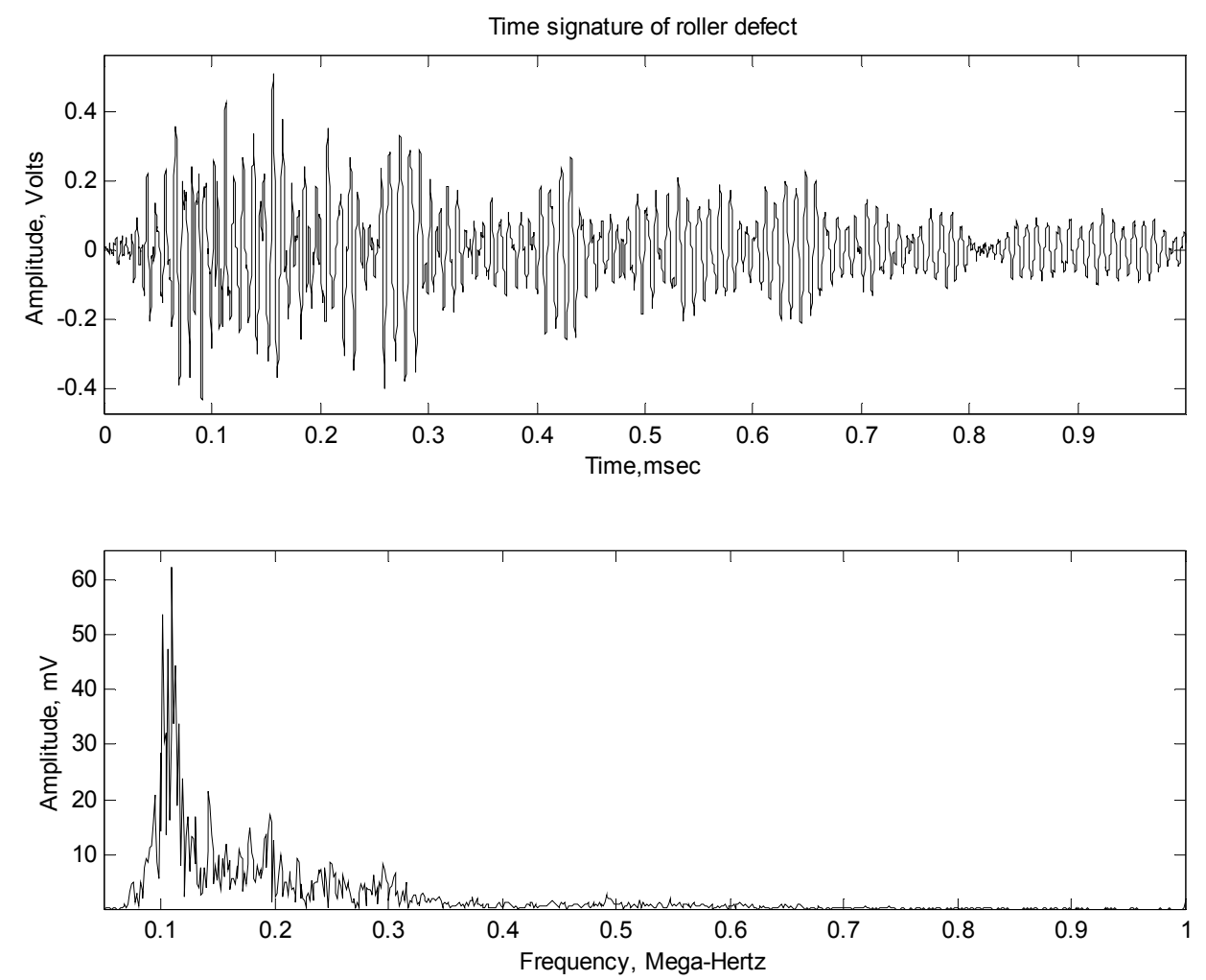

Figure 6 Typical time signature with corresponding frequency spectrum, roller defect

\subsubsection{Grease contamination}

A typical signature for grease contamination, with, corresponding frequency spectrum, is displayed in figure 7. 

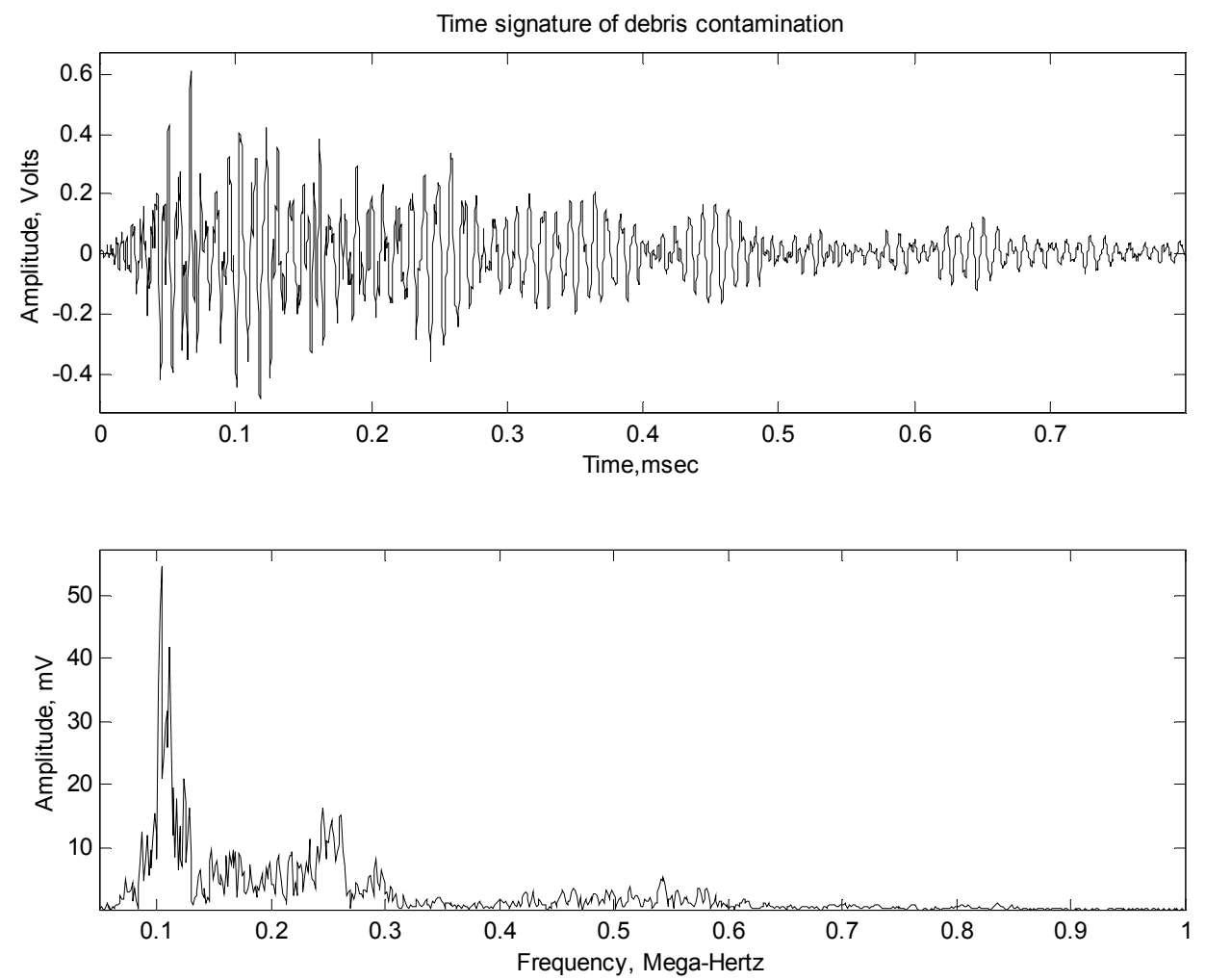

Figure 7 Typical time signature with corresponding frequency spectrum, grease contamination

\section{Classification and Signal processing}

Typical acoustic emission features, amplitude and energy, were employed to identify and classify SW signatures associated with various seeded defects and background noise. A total of thirty SW signatures were obtained for each simulated fault condition. The maximum amplitude $(\mathrm{mV})$ and energy $\left(\mathrm{Vsec} 10^{-3}\right)$ of each SW signature was extracted. These values were plotted against the associated SW signature for the varying greases 
employed, see figures 8 to 11 . To aid interpretation, a polynomial fit based on a $5^{\text {th }}$ order model was applied.

Definitions for figures 8 to 11 :-

\begin{tabular}{|l|l|}
\hline ORD & Outer race defect \\
IRD & Inner race defect \\
RD & Roller defect \\
GOOD & Good bearing \\
DEBRIS & Debris contamination \\
\hline
\end{tabular}




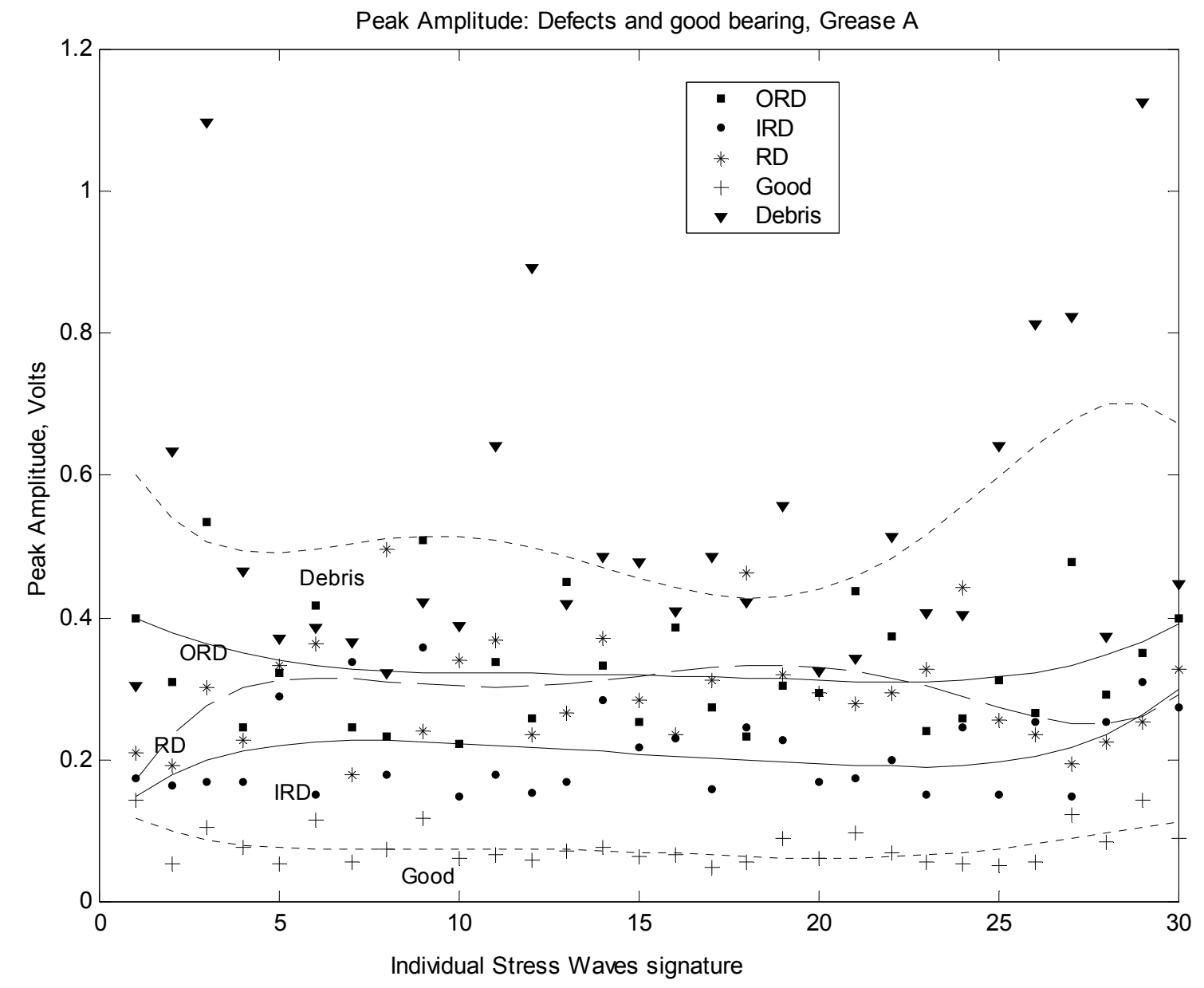

Figure 8 Peak amplitude values for all defects, grease type A. 


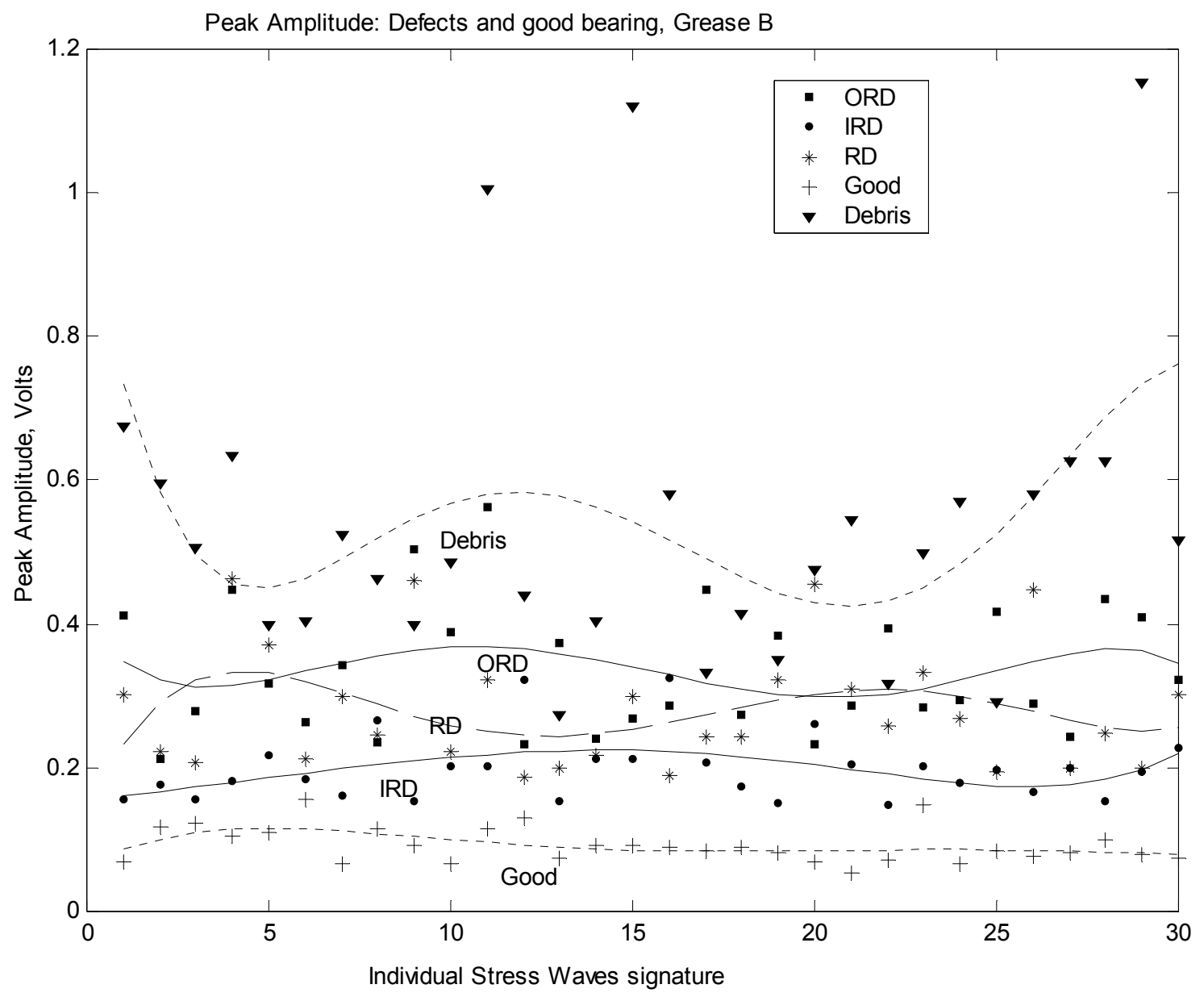

Figure 9 Peak amplitude values for all defects, grease type B. 


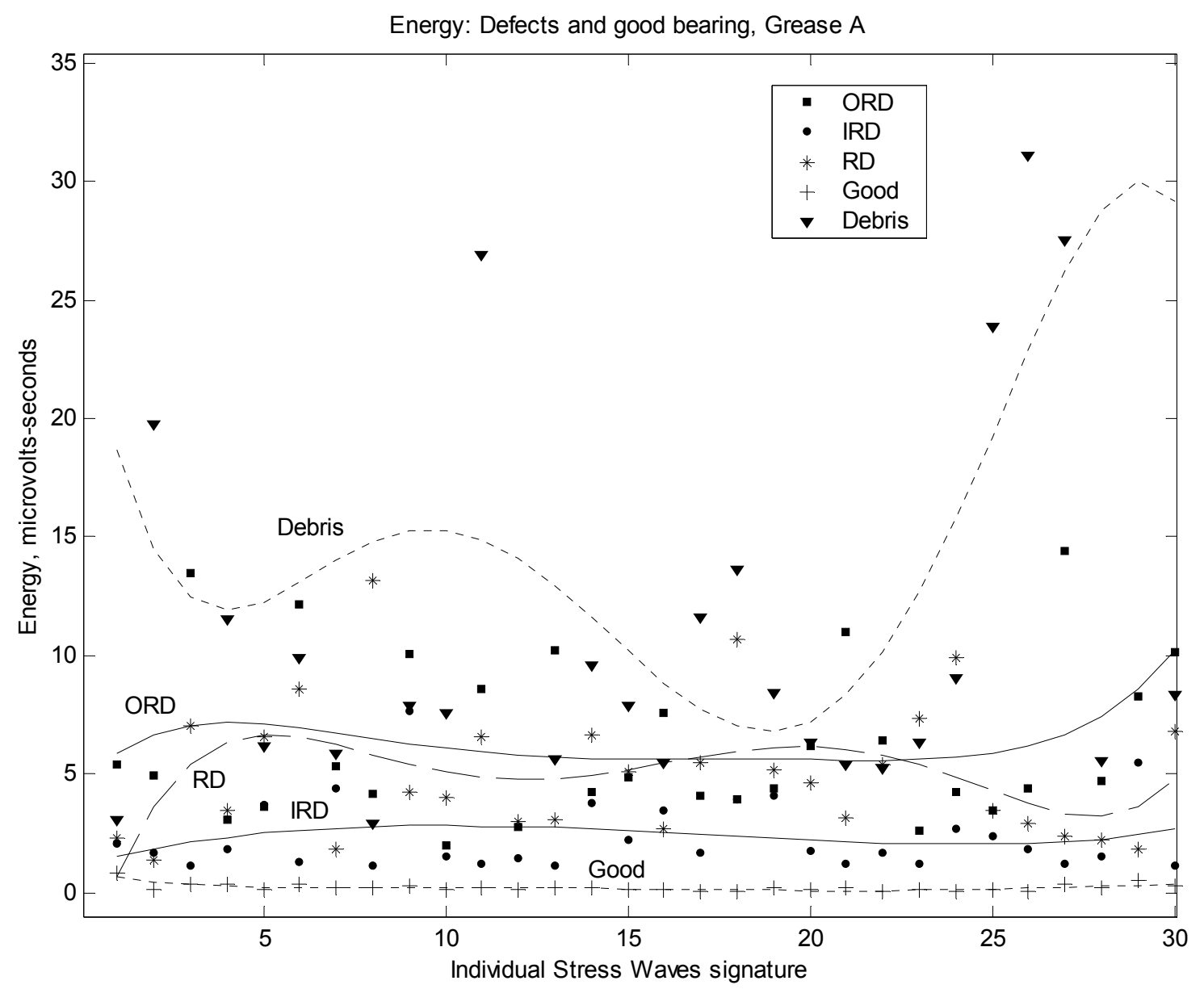

Figure 10 Energy values for all defects, grease type A. Note: Values for SW signatures 3 and 12 were 41.74 and 40.60 (micro-volts-seconds) respectively. These values were included in the computation of the polynomial fit. 


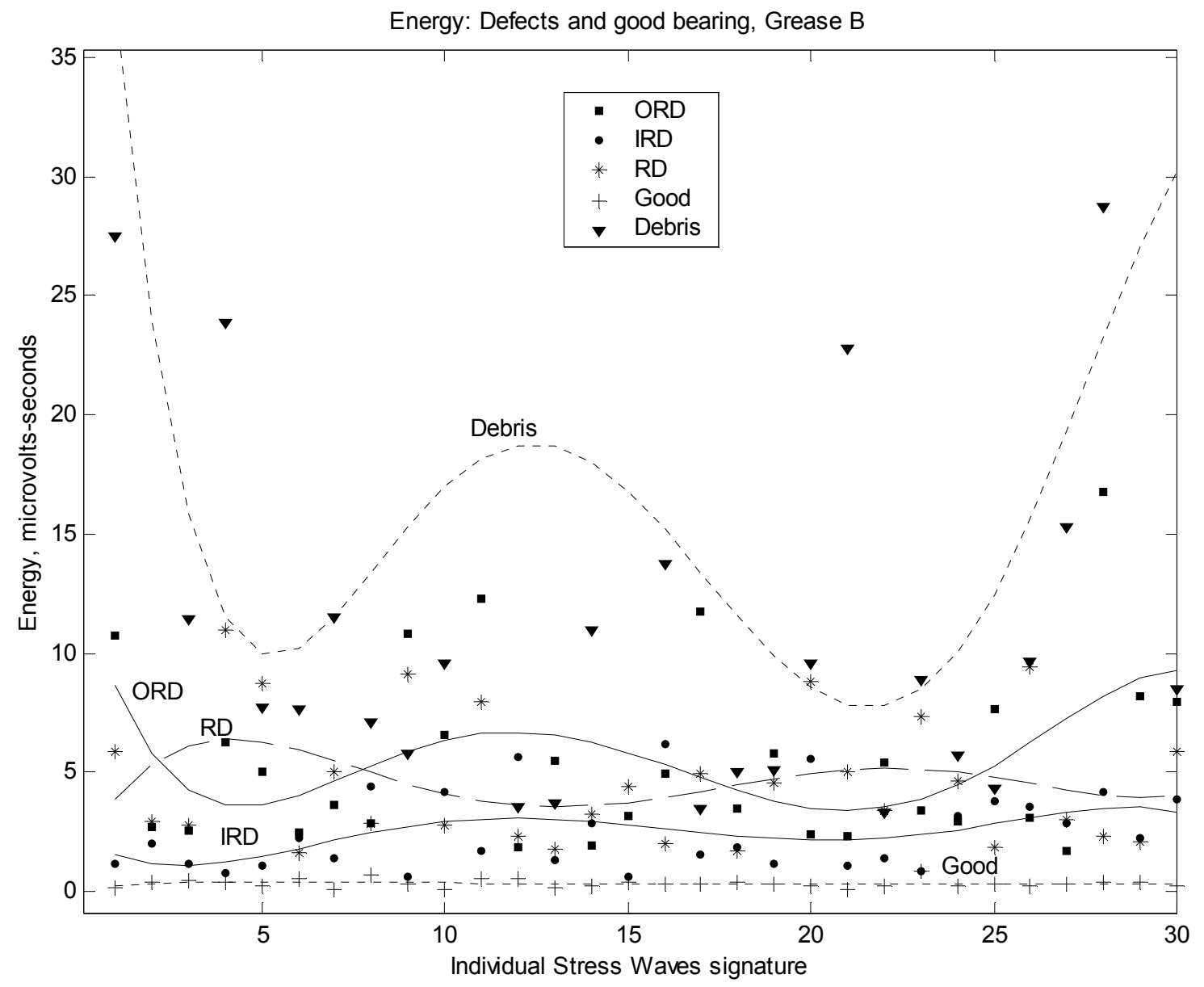

Figure 11 Energy values for all defects, grease type B. Note: Values for SW signatures 3 and 12 were 35.95 and 48.60 (micro-volts-seconds) respectively. These values were included in the computation of the polynomial fit.

Thus far, the process of distinction has been applied to data obtained under ideal experimental conditions, where all the influencing factors are controlled. It was therefore though prudent to establish a relatively more robust technique for classifying and grouping the various fault conditions. The philosophy behind this was that on-site, the interpretation of signatures from real operational bearings might not be distinguishable by extracting parameters such as amplitude and energy. This is due to the very random 
nature of noise that could be generated on bearings operating under varying loads and environments. Furthermore, the levels of background noise, which would vary from one bearing to another, could be comparable with levels of our fault simulations; therefore, identification of a defect would be impossible. Background noise simulated in the laboratory for this investigation was under a controlled non-hostile environment. Mba et. al. $(1,2)$ has shown that transmission paths can aid in source location of SW signatures by classification of Auto-Regressive (AR) coefficients associated with each SW. Since the defects simulated in this paper originate from different parts of the bearing, having different transmission paths to the receiving transducer, SW generated from these defect positions will have characteristic features that are unique to their particular transmission path. As it has been shown $(1,2)$ that AR coefficients can represent the shape of a signature, which in turn is dependent on transmission path to the receiving sensor, classification based on an AR model was undertaken.

The computation of AR coefficients is derived from linear prediction and a review of parametric models such as AR has been detailed $(26,27,28)$. Application of the Forward Prediction Error and Akaike Information Criteria $(26,27)$, used for the selection of the optimal AR model order on various stress waves generated on the test-rig, showed that a $15^{\text {th }}$ order model was sufficient for characterisation of SW signatures associated with seeded defects and background noise. The computation of AR coefficients was undertaken with the Levinson-Durbin algorithm (26). The use of a $15^{\text {th }}$ order model implied that each SW signature was represented by sixteen coefficients. The process of classifying these coefficients employed a cluster technique known as K-means (29). This 
is a non-hierarchical technique that measures the Euclidean distances between the centroid value of the AR coefficients associated with each signature. This technique was employed and detailed by Mba et. al $(1,2)$ and initially involves grouping the coefficients with the least Euclidean. Next, the group's centroid position is recalculated, and the AR coefficients with the minimum distance to the newly formed group are clustered with it. This procedure is repeated every-time a component is added to the cluster until all the components are grouped. The results were displayed on dendrograms (29).

Auto-Regressive coefficients associated with SW signatures from inner, outer and roller defects, and grease contamination, were compared with those from operational background noise by clustering, see figures 12 to 21 . In addition, all AR coefficients associated with all simulated faults were grouped and clustered, see figures 22 to 27 .

Definitions for figures 12 to $27:-$

\begin{tabular}{|l|l|}
\hline o & Outer race defect \\
$\mathrm{i}$ & Inner race defect \\
$\mathrm{r}$ & Roller defect \\
bgh & Background noise \\
$\mathrm{d}$ & Debris contamination \\
$\mathrm{n}$ & Noise \\
\hline
\end{tabular}


Classification of good bearing SW signaturesl using the centroid value of AR coefficients, Grease A

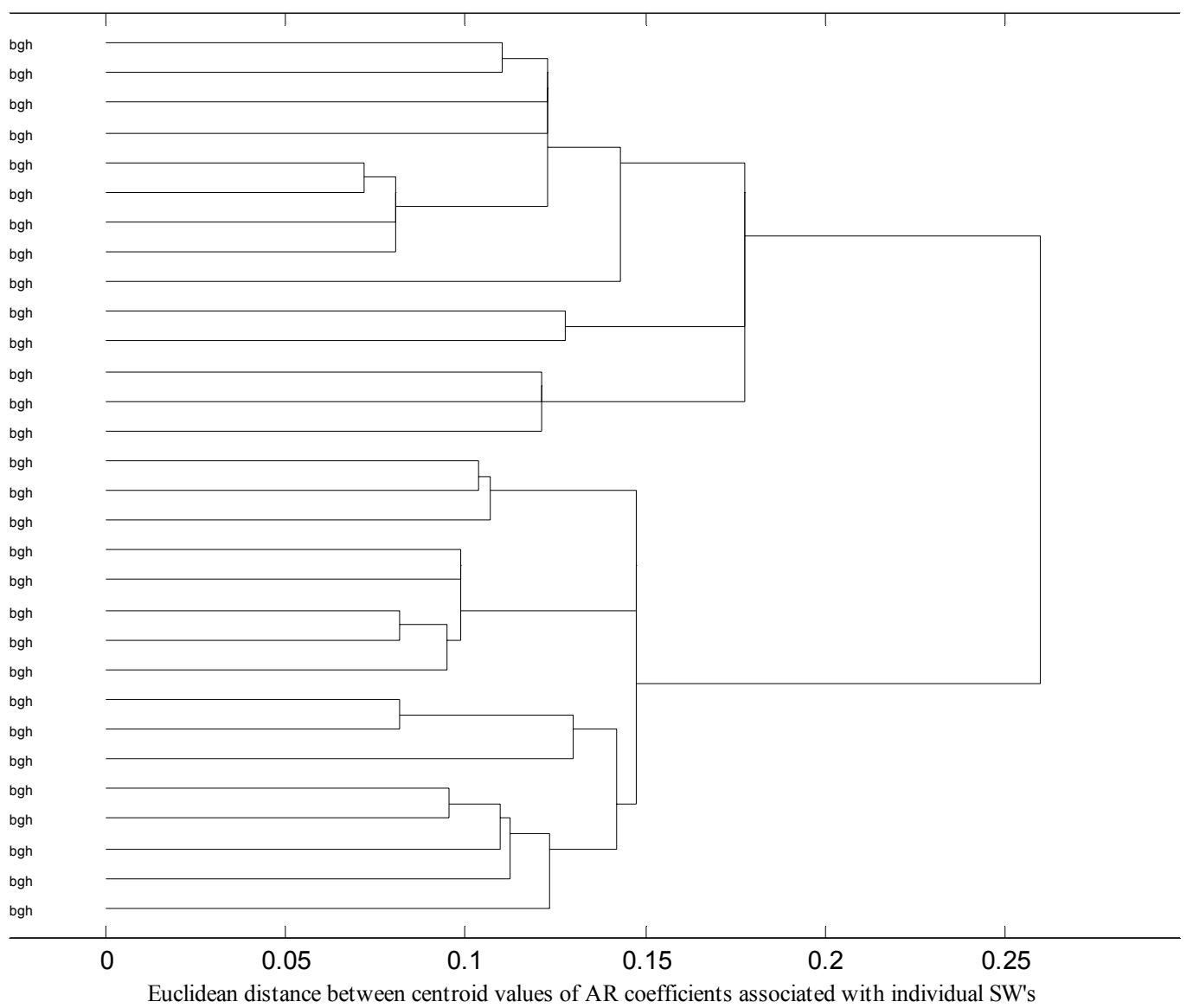

Figure 12 Classification of SW's associated with background noise of a good bearing, grease type $\mathrm{A}$. 
Classification of good bearing SW signatures using the centroid value of AR coefficients, Grease B

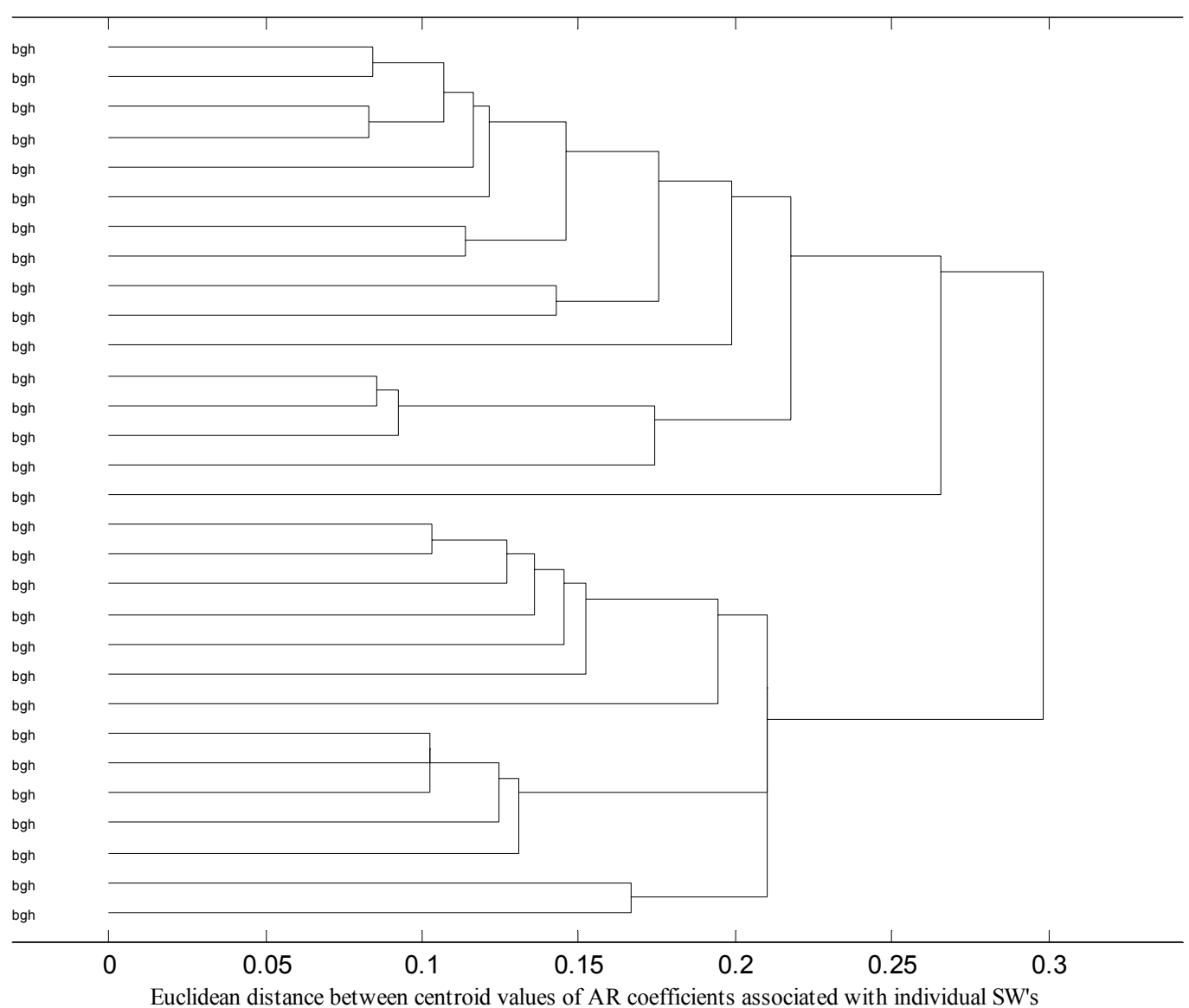

Figure 13 Classification of SW's associated with background noise of a good bearing, grease type $B$. 
Classification using the centroid value of AR coefficients, ORD and noise, Grease A

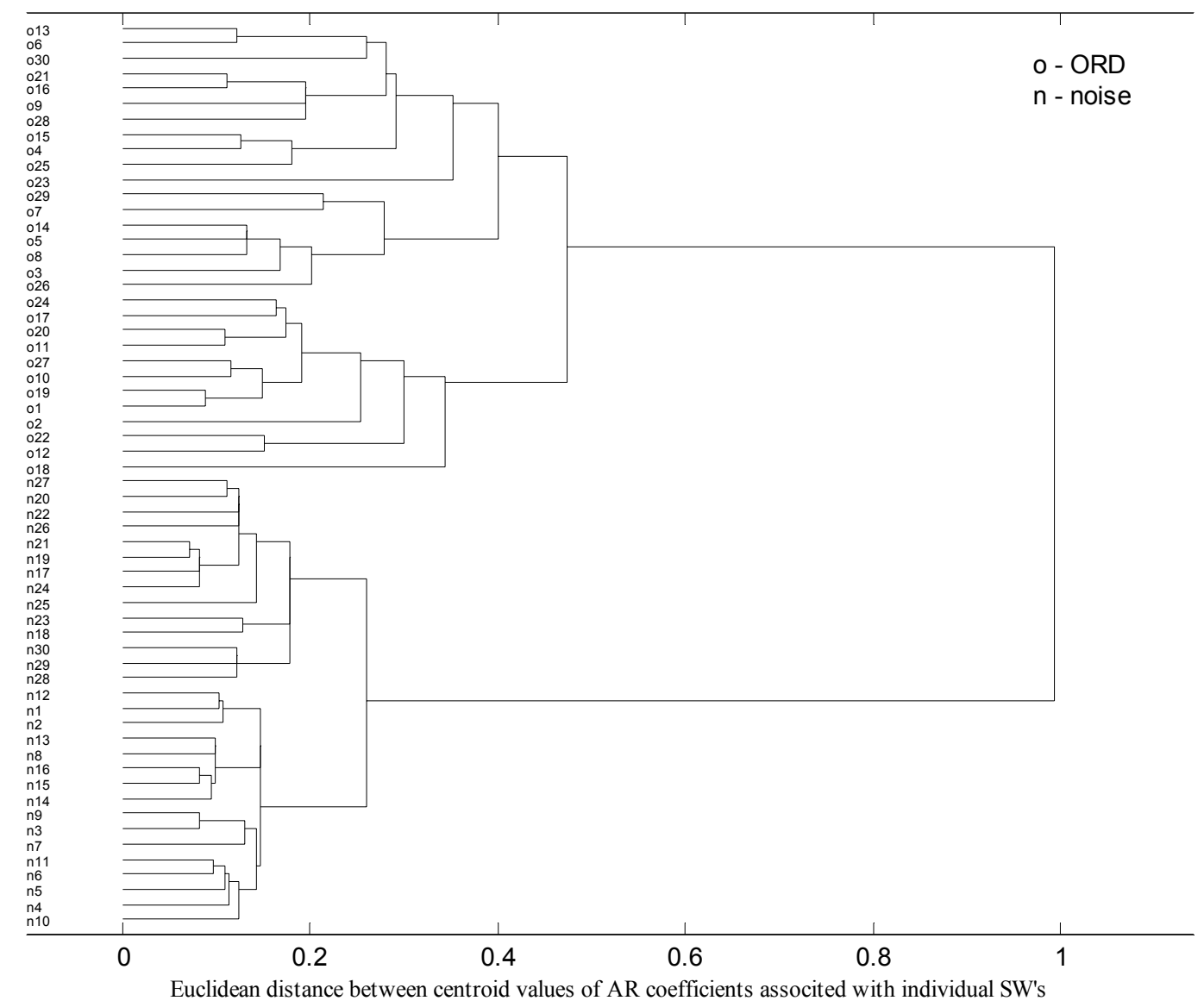

Figure 14 Classification of SW's associated with background noise and outer race defects, grease type $A$. 


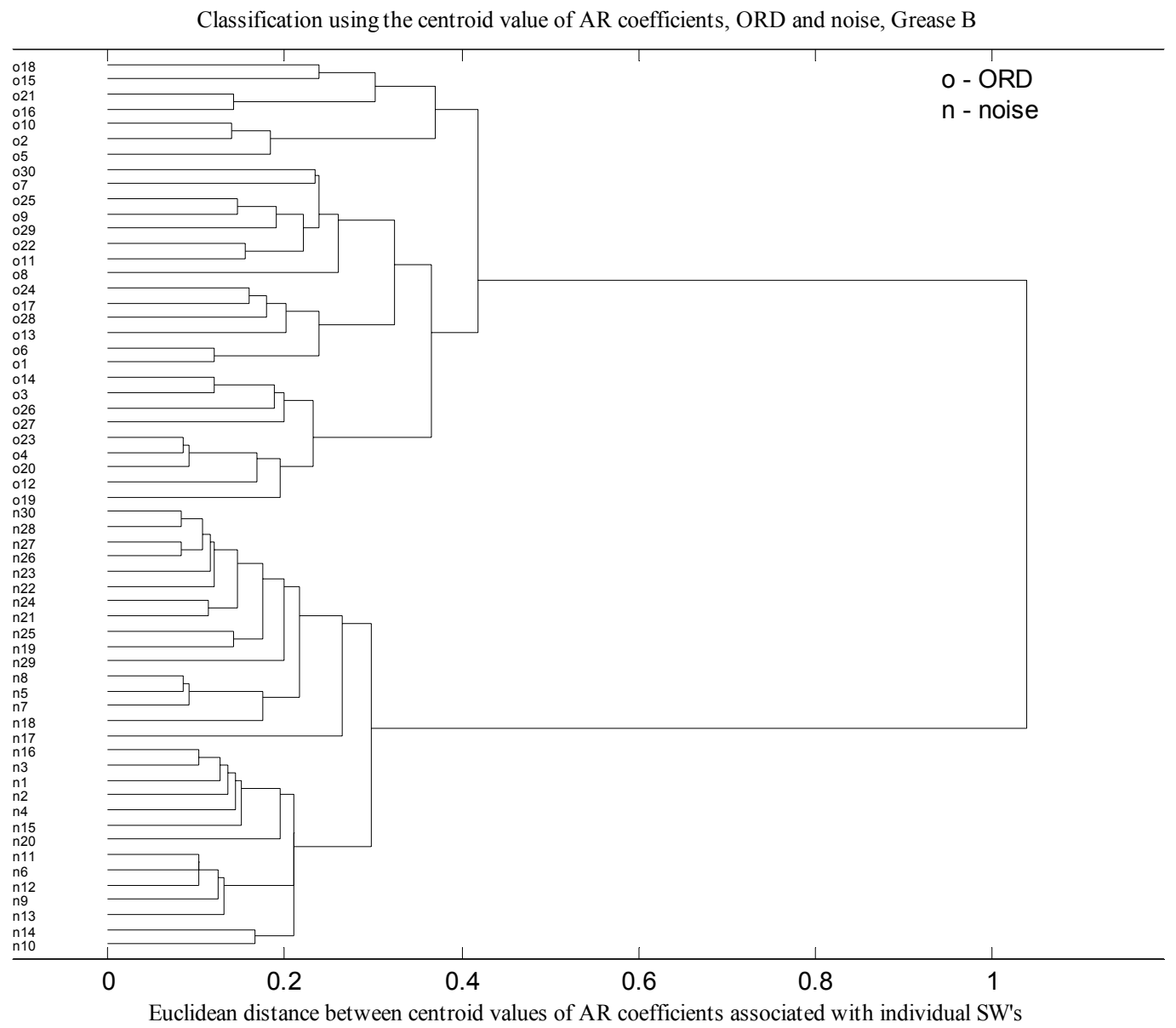

Figure 15 Classification of SW's associated with background noise and outer race defects, grease type $B$. 
Classification using the centroid value of AR coefficients, RD and noise, Grease A

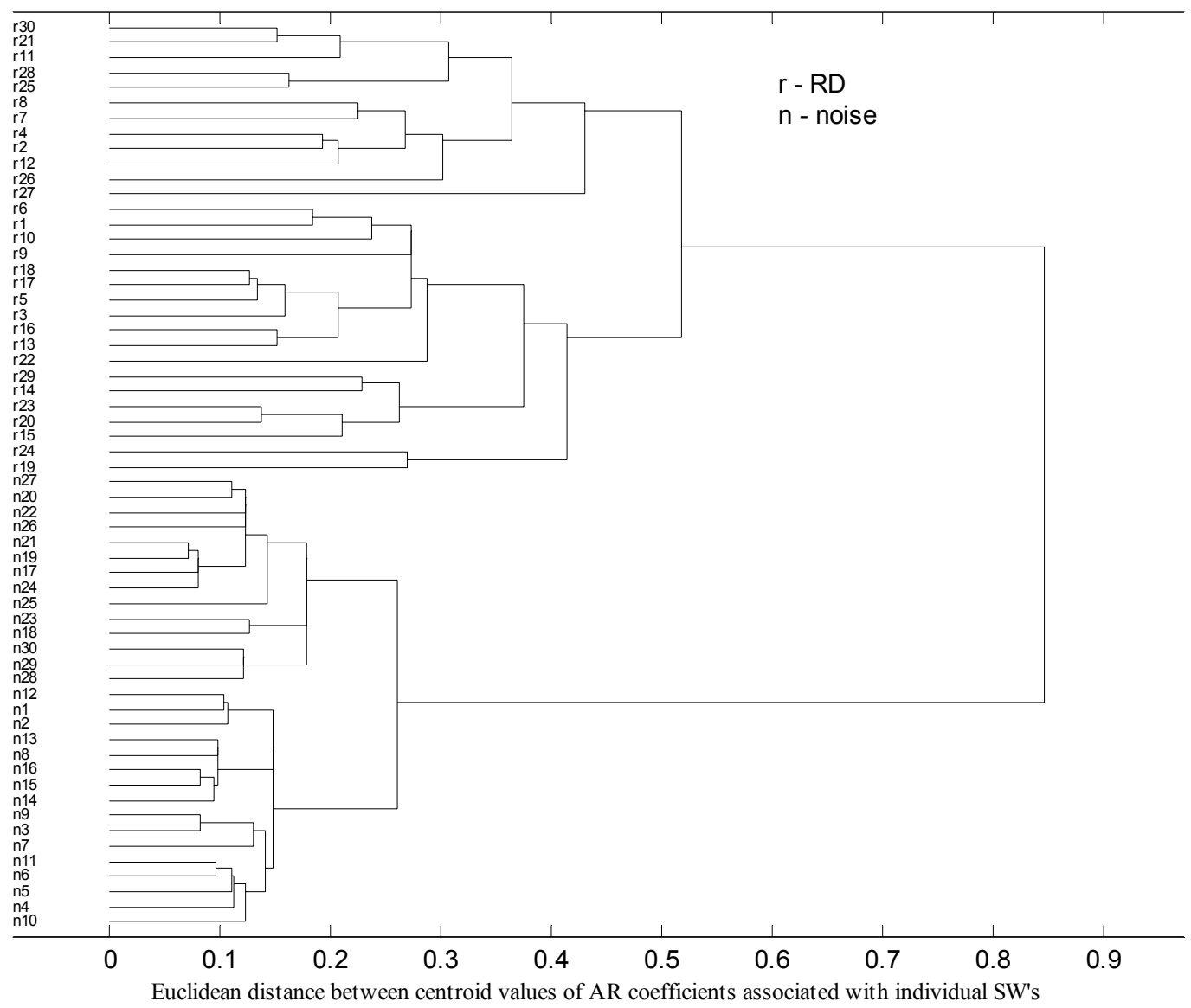

Figure 16 Classification of SW's associated with background noise and roller defects, grease type A. 
Classification using the centroid value of AR coefficients, RD and noise, Grease B

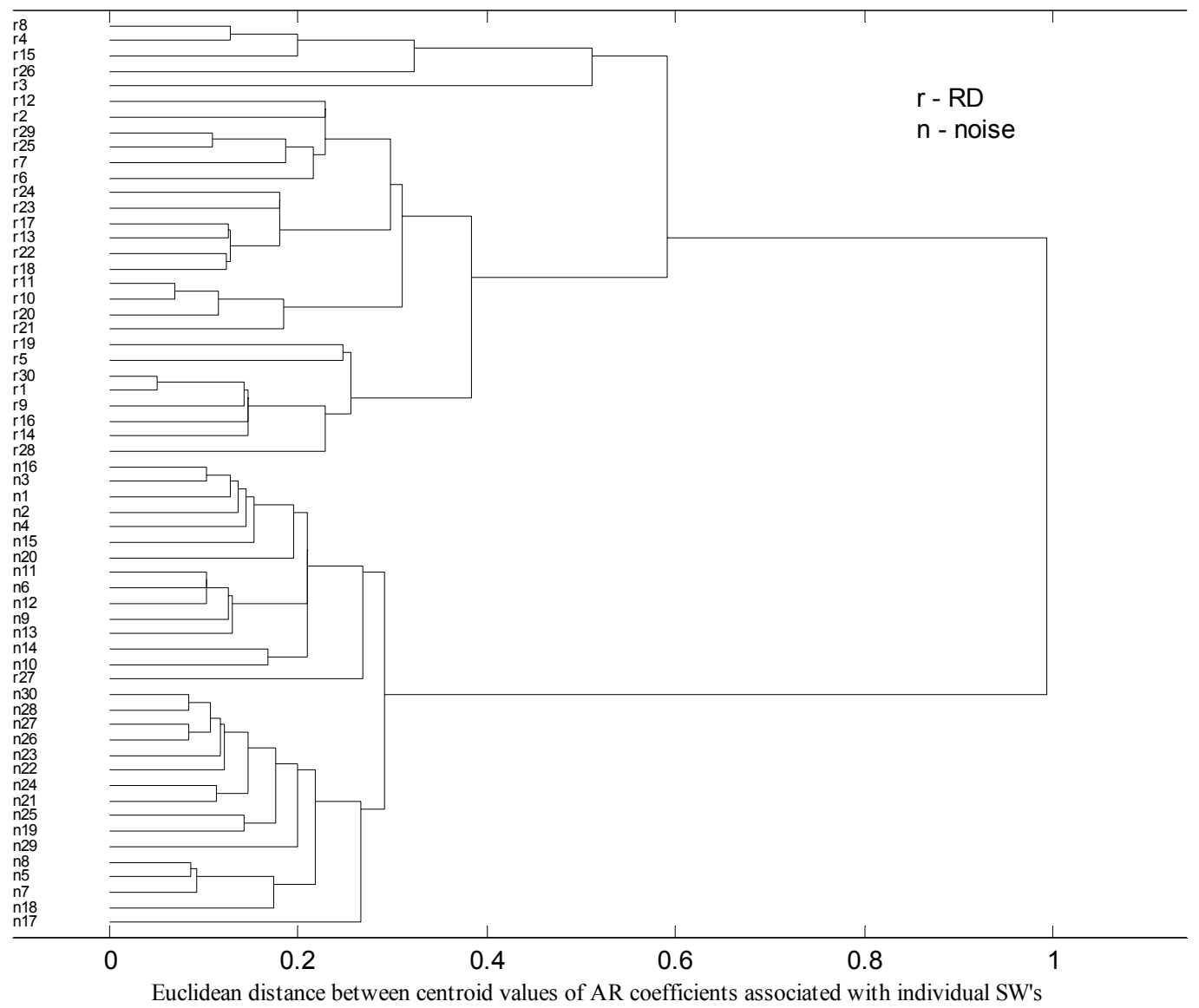

Figure 17 Classification of SW's associated with background noise and roller defects, grease type B. 
Classification using the centroid value of AR coefficients, IRD and noise, Grease A

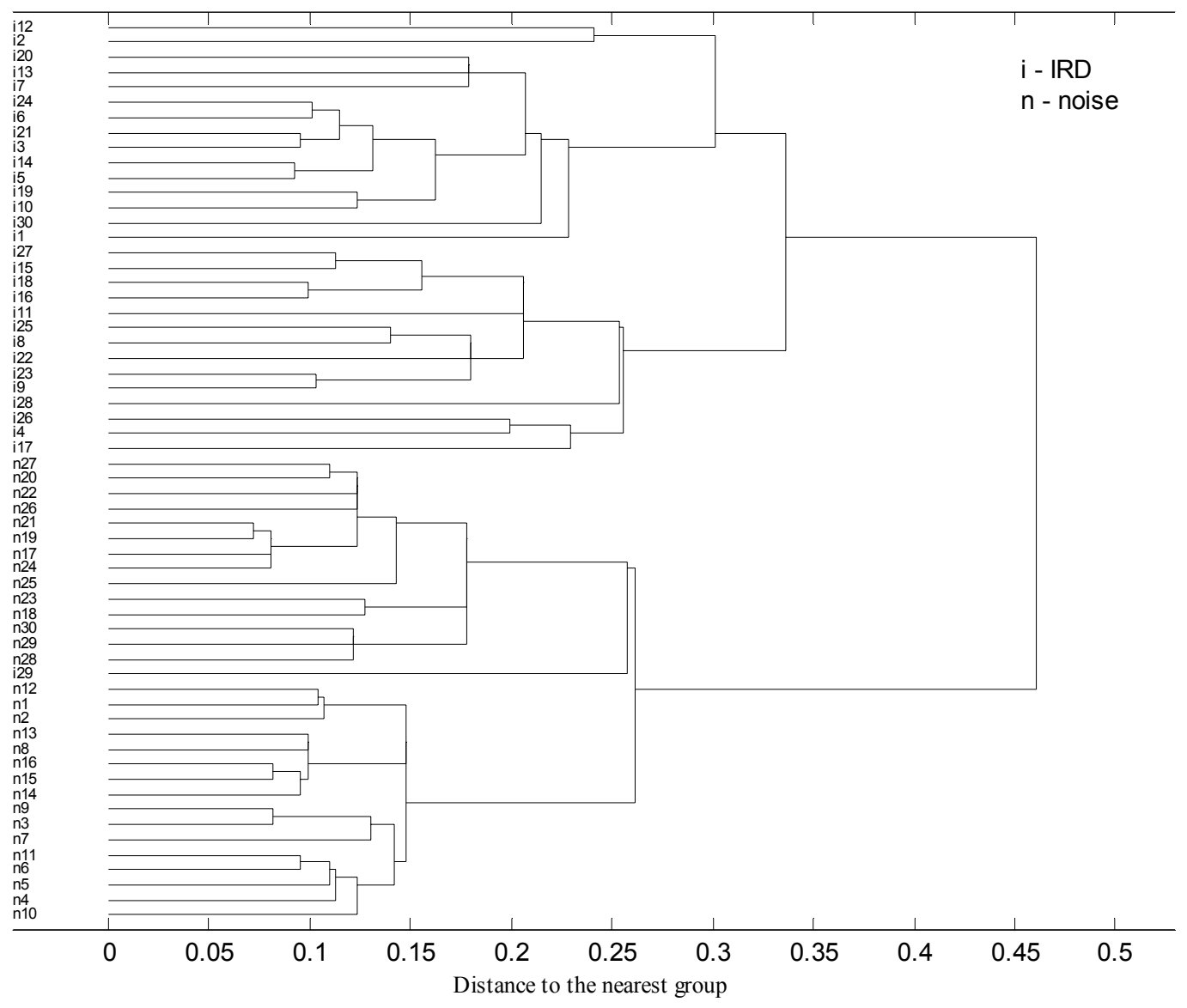

Figure 18 Classification of SW's associated with background noise and inner race defects, grease type A. 


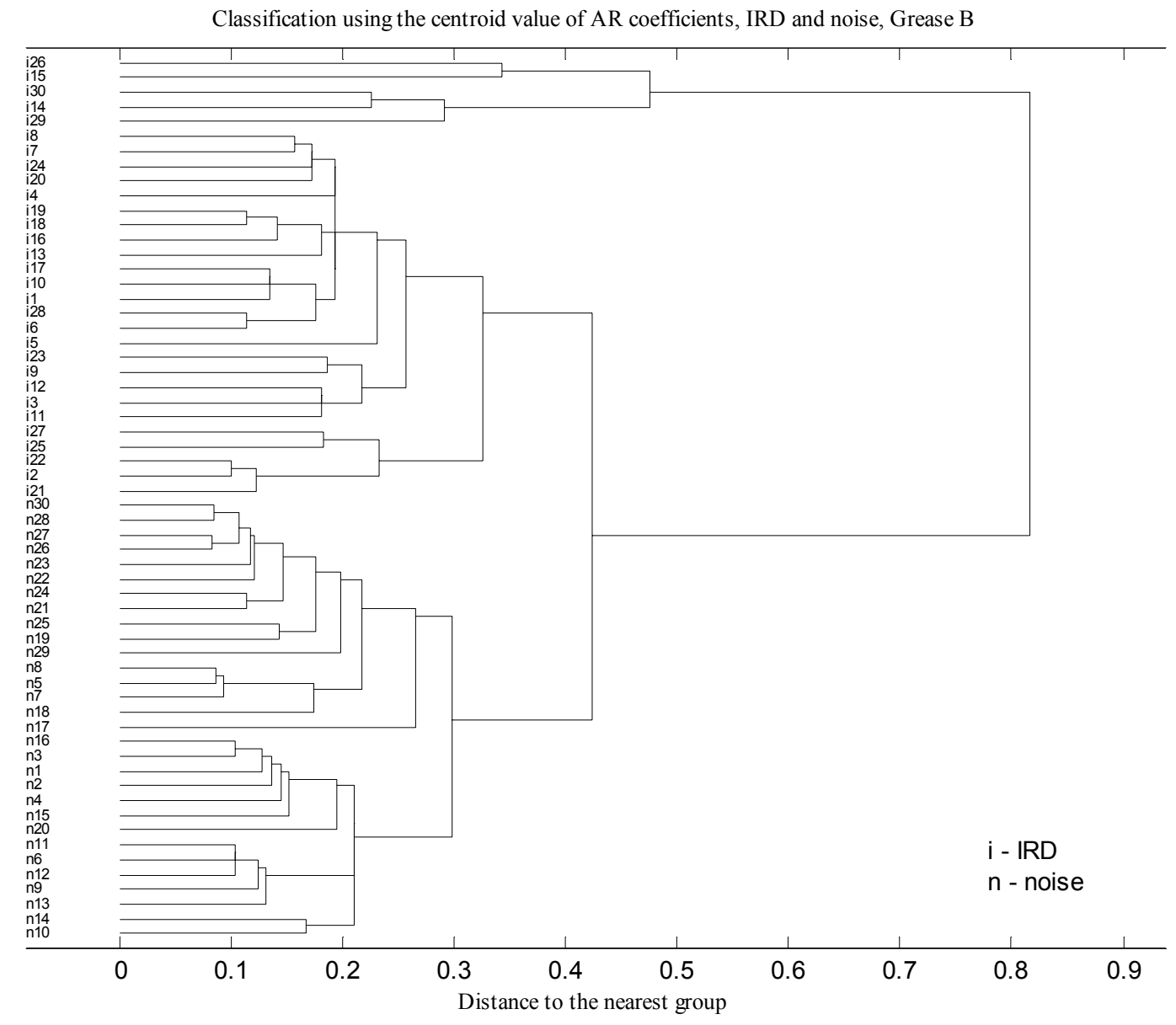

Figure 19 Classification of SW's associated with background noise and inner race defects, grease type $B$. 


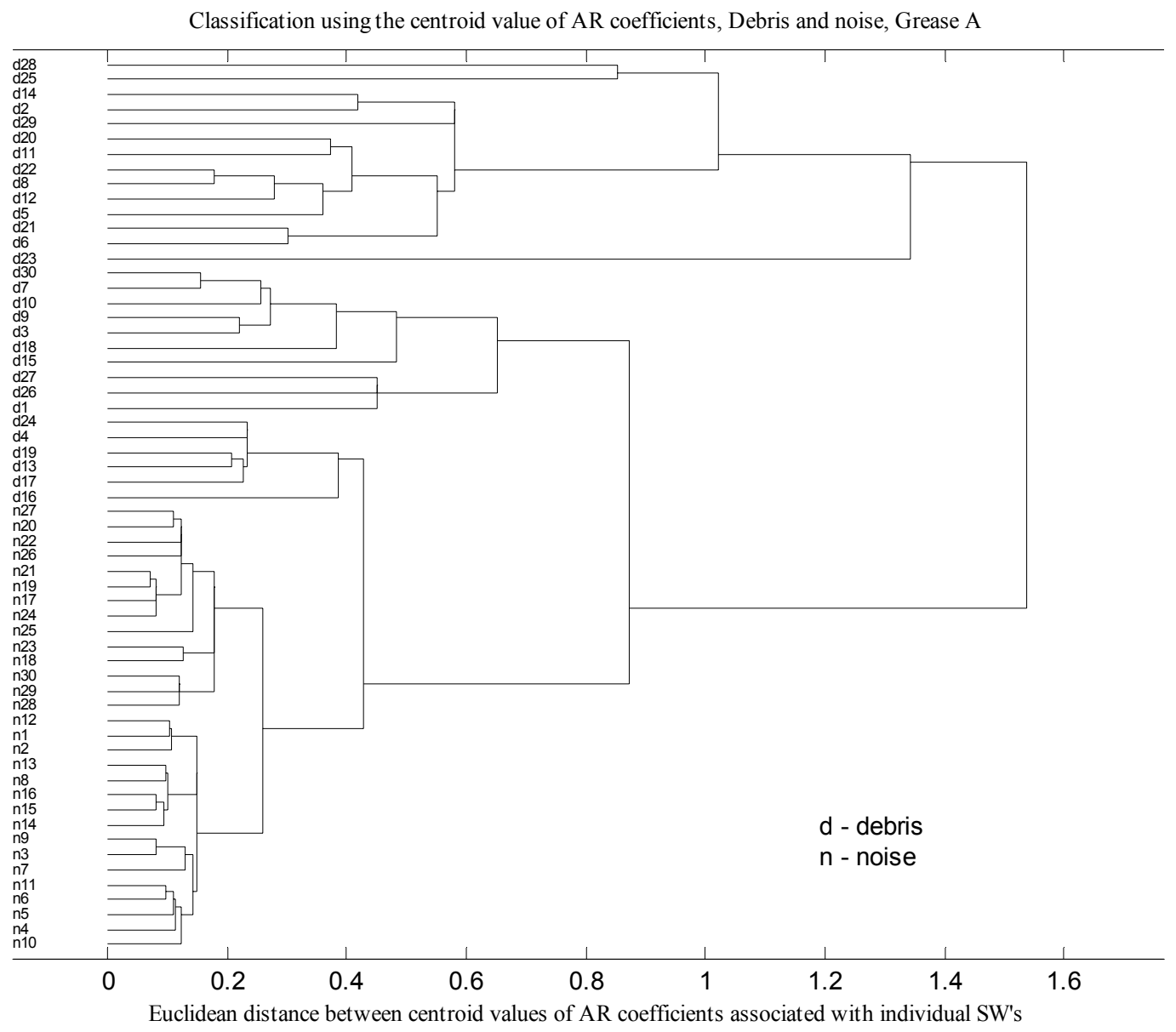

Figure 20 Classification of SW's associated with background noise and grease contamination, grease type A. 


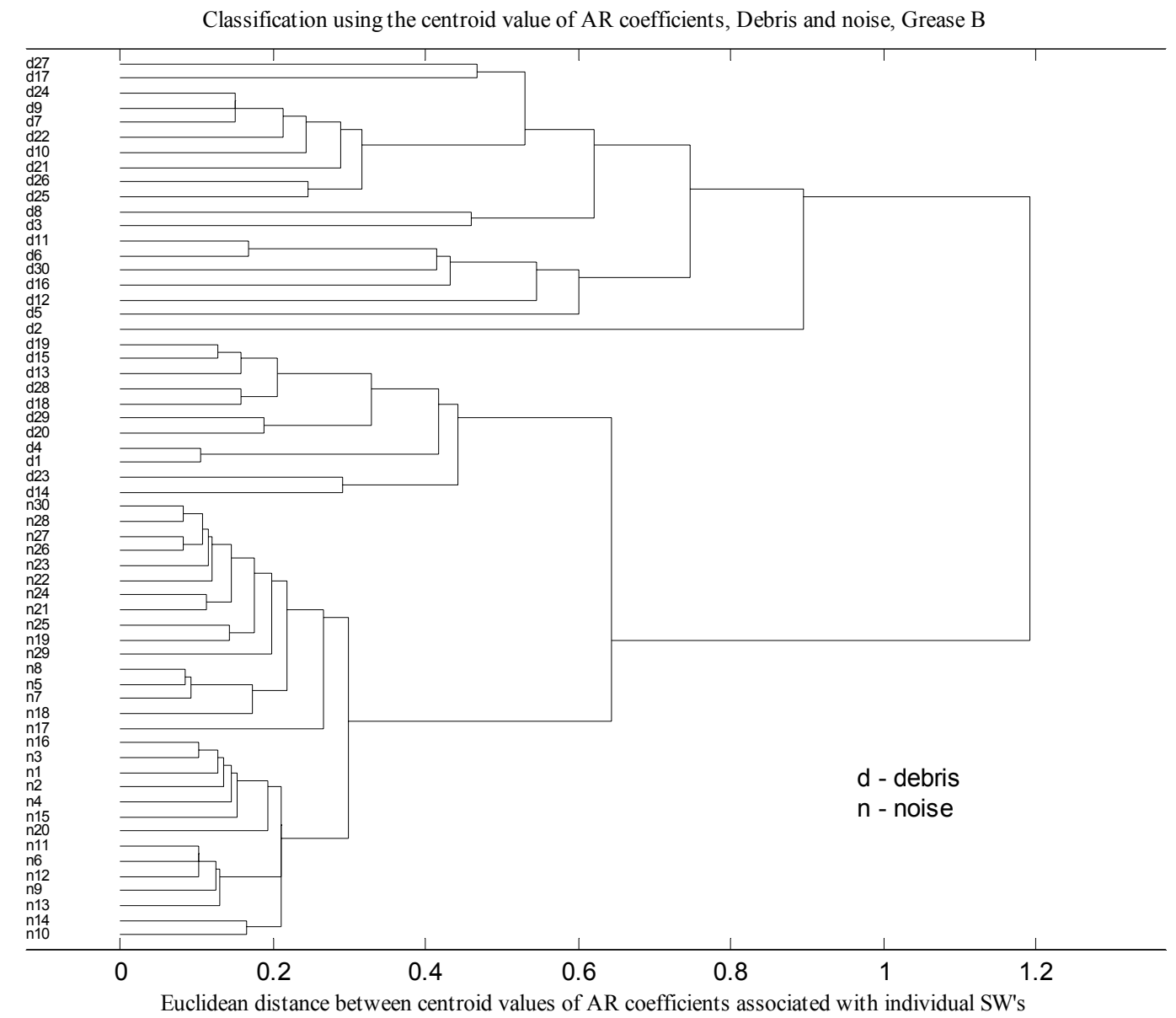

Figure 21 Classification of SW's associated with background noise and grease contamination, grease type $B$. 
Classification using the centroid value of AR coefficients, All defects and noise, Grease A

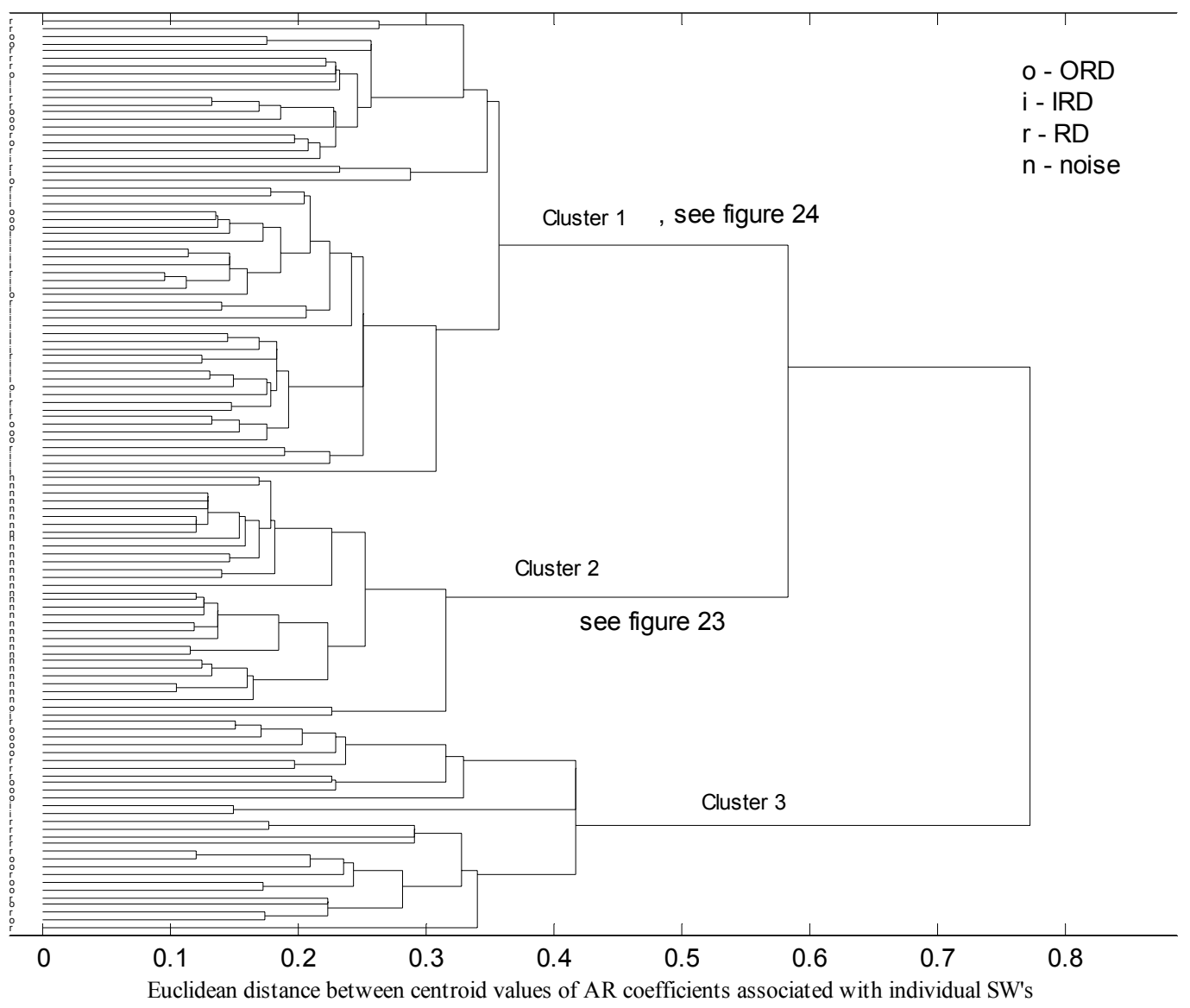

Figure 22 Classification of SW's associated with background noise and all fault conditions, grease type A. 
Classification using the centroid value of AR coefficients, All defects and noise, Grease A

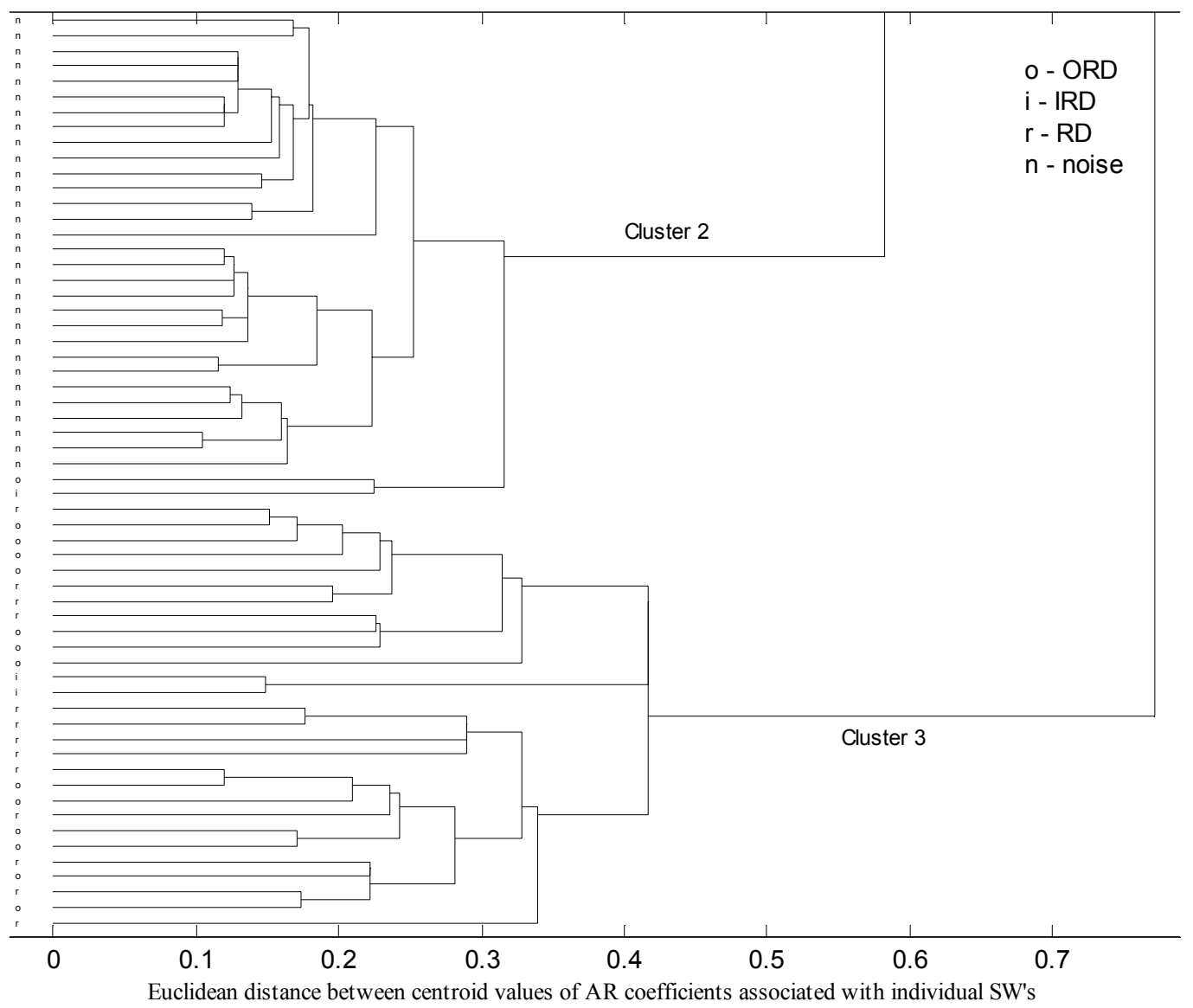

Figure 23 Close-up view of clusters 2 and 3 in figure 22, grease type A. 
Classification using the centroid value of AR coefficients, All defects and noise, Grease A

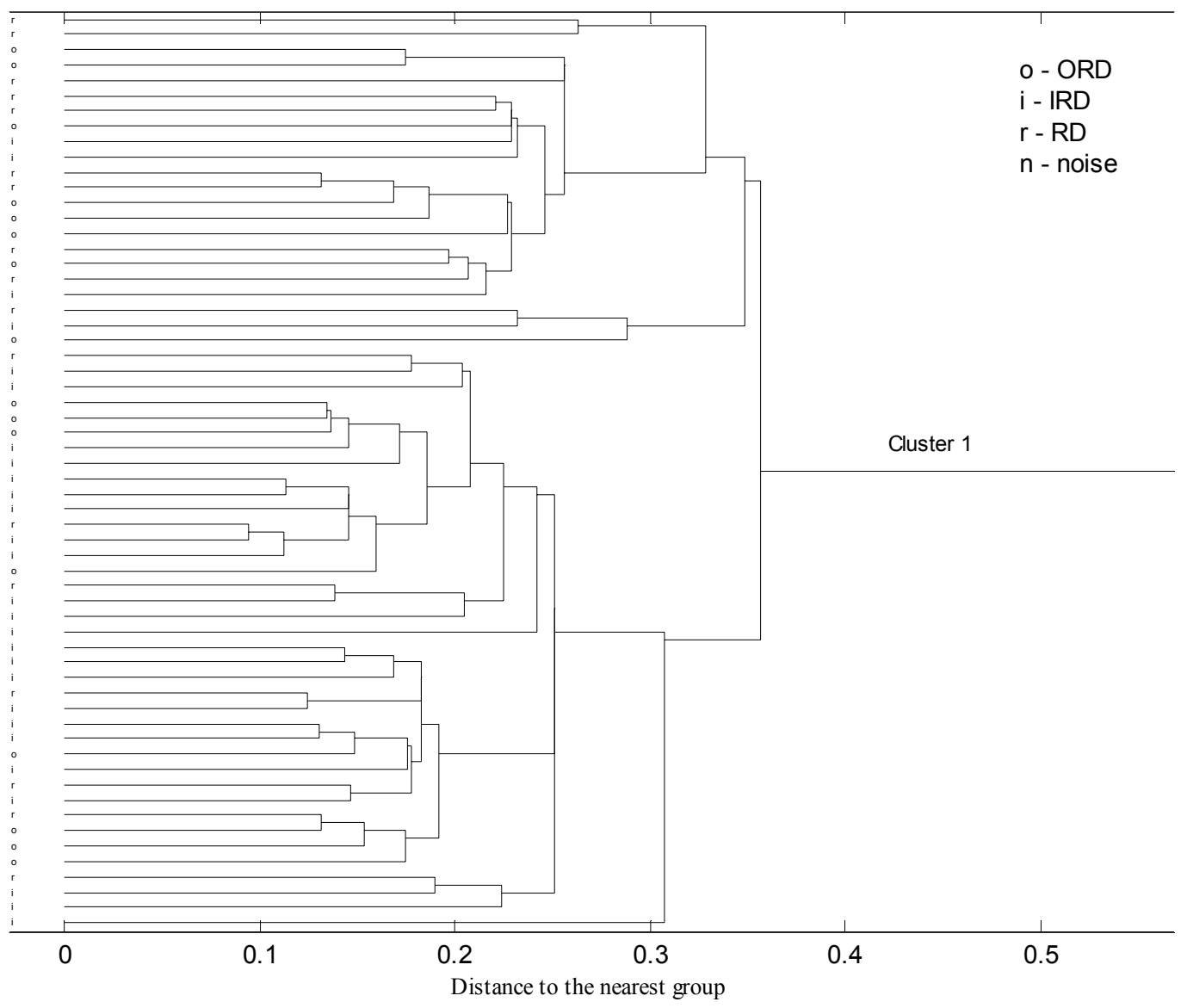

Figure 24 Close-up view of cluster 1 in figure 22, grease type A. 
Classification using the centroid value of AR coefficients, All defects and noise, Grease B

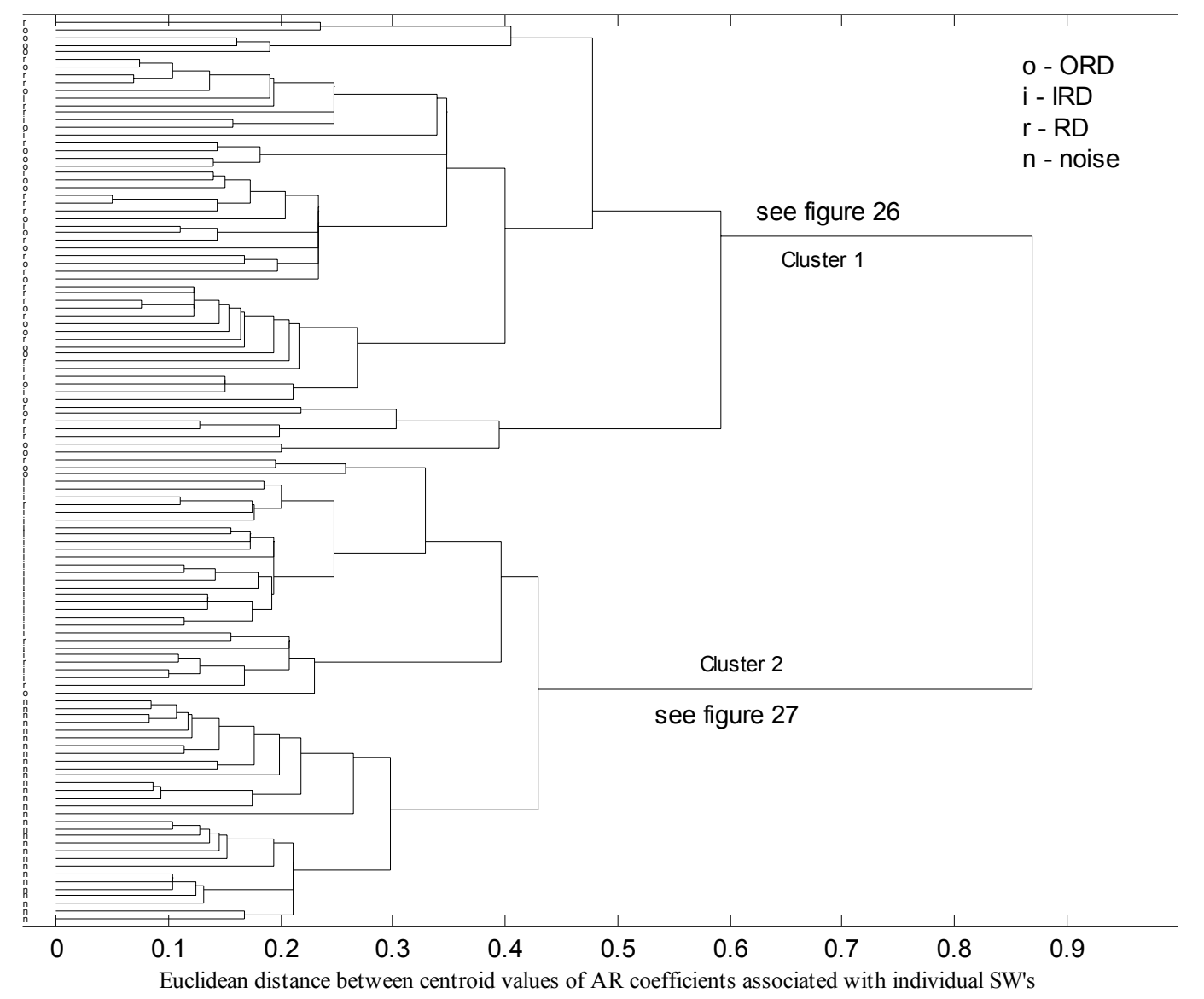

Figure 25 Classification of SW's associated with background noise and all fault conditions, grease type B. 
Classification using the centroid value of AR coefficients, All defects and noise, Grease B

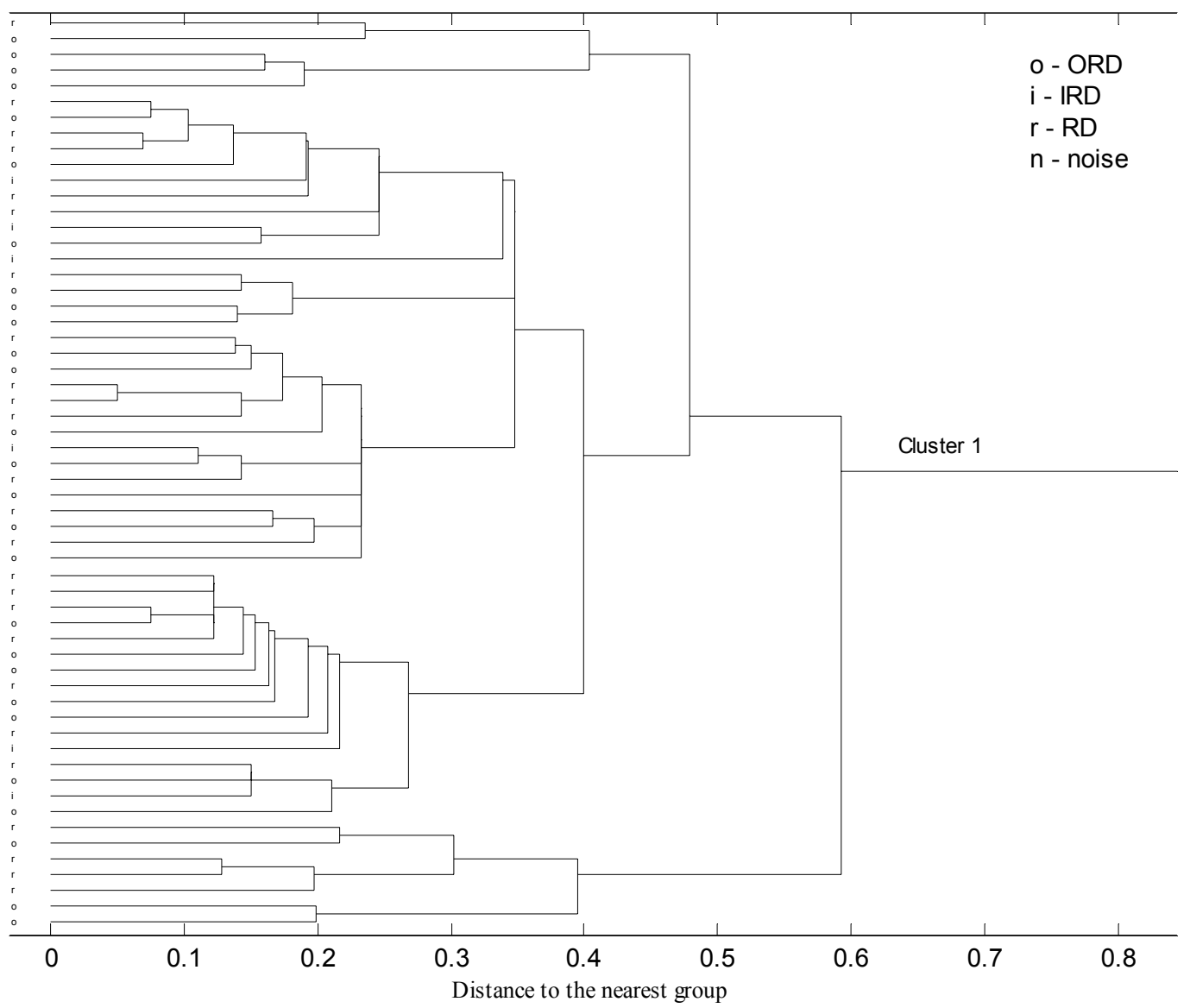

Figure 26 Close-up view of cluster 1 in figure 25, grease type B. 
Classification using the centroid value of AR coefficients, All defects and noise, Grease B

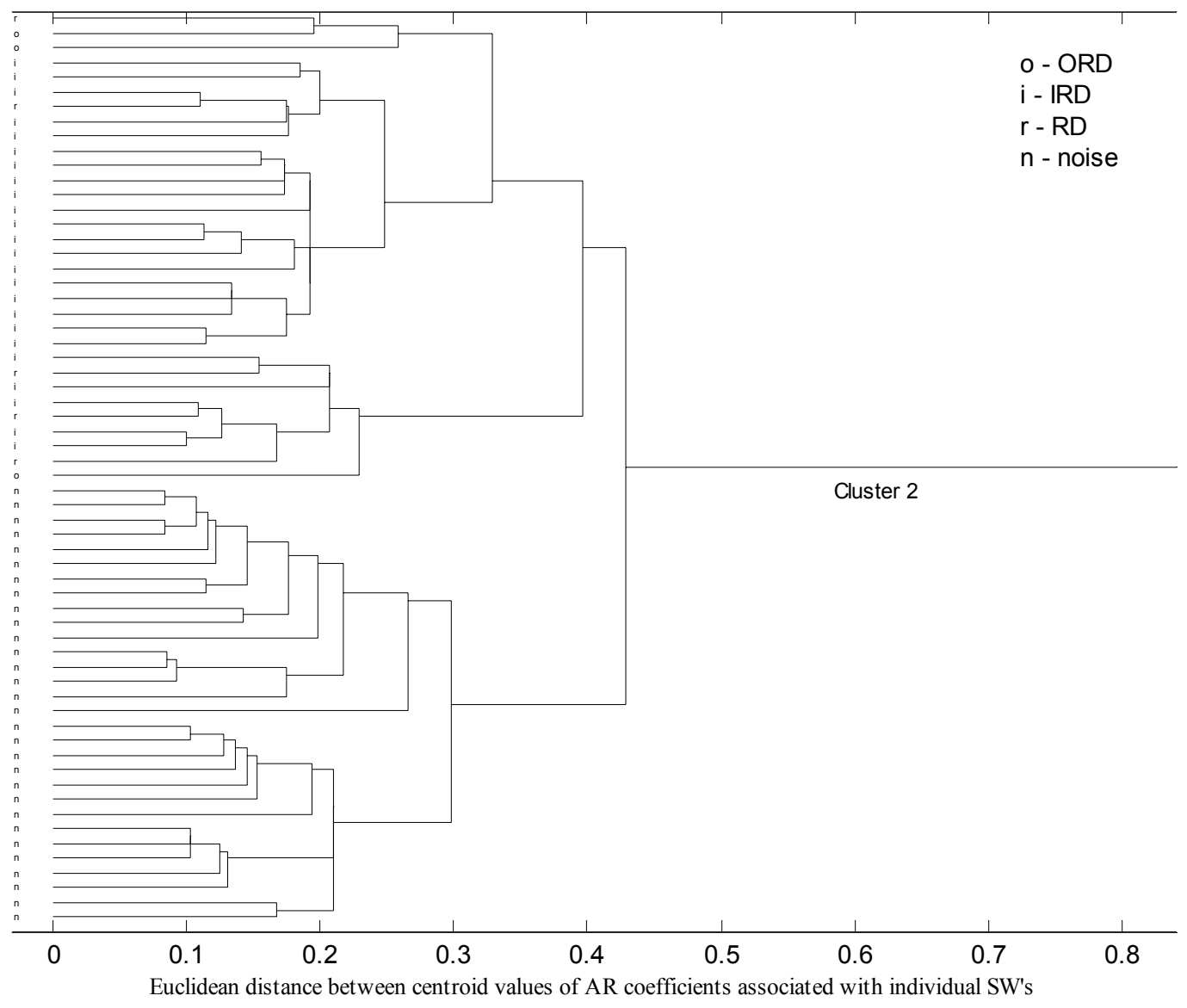

Figure 27 Close-up view of cluster 2 in figure 25, grease type B.

\section{Discussions}

Stress waves emitted from defect simulations were attributed to the relative movements between mating components. Signatures associated with operational baseline data (noise) showed the maximum amplitude to be in the order of $170 \mathrm{mV}$. By setting a trigger level 
above this value, and undertaking individual fault simulations, only signatures relating to a specific fault condition were captured.

\subsection{Electro Discharge Machine (EDM) technique}

Experimental observations and analysis of the SW signatures associated with the EDM seeded defects revealed that the generation of SW's was random in nature, as with operational baseline noise. For instance, having seeded a fault onto the outer race, it was expected that SW's would be generated at a frequency corresponding to the outer-race passage frequency $(5.65 \mathrm{rpm})$. However, no SW signature was detected. This scenario applied to all defects seeded with the EDM technique and implied that there is a limit of surface distortion below which a fault will pass undetected by the monitoring system. This is seen as a drawback to the technique presented, suggesting that very early stages of surface defect may go undetected until such a time that the defects has 'matured' to a critical level of surface distortion.

\subsection{Faults seeded with the Spark eroding technique}

Defects seeded with the spark erosion technique emitted SW signatures for all simulations. During simulation of the outer race defect (ORD), SW activity occurred approximately every ten seconds. This corresponded to the calculated outer-race passage frequency of $5.65 \mathrm{rpm}$. Also, observations showed that in some instances more than one SW signature was emitted as the roller passed the outer-race defect. This was attributed 
to the fact that each roller had to rub against the full $3 \mathrm{~mm}$ width of the defect. As a direct result, SW can be generated at various positions along the $3 \mathrm{~mm}$ length of the defect. Furthermore, SW signatures associated with the inner-race defect (IRD) and roller defect (RD) were only detected for a certain period of time, i.e., did not occur continuously throughout one complete revolution of the cage. This phenomenon was due to the fact that SW was only generated when the IRD and RD were in the loading zone.

Typical SW's detected from simulations showed their duration to be no more than $1 \mathrm{msec}$. The corresponding frequency spectra ranged from $100 \mathrm{KHz}$ to $600 \mathrm{KHz}$, though the strength at varying frequencies differed for different fault conditions.

Comparisons of the amplitude and energy levels associated with individual SW's showed trends that were distinguishable, for the two types of grease. The lowest amplitude and energy values were associated with operational noise. Furthermore, a gradual increase in amplitude and energy levels was evident for inner-race, roller, outer-race defects and grease contamination respectively. A polynomial fit was employed to highlight this trend, see figures 8 to 11 .

The increasing values of amplitude and energy were attributed to the closeness of the source of defect to the sensor. For instance, as the sensor was placed on the bearing housing, it was expected that the greatest amplitude/energy of SW should come from the outer race (under constant load conditions). The outer race rests on the bearing housing, consequently, the SW only has two interfaces to overcome to reach the receiving sensor, 
i.e., the interface between the outer race and the housing, and, the housing and the receiving sensor.

Lower values of amplitude/energy were emitted from the inner race defect. As the signature has more interfaces to overcome before reaching the receiving sensor, it was not surprising that attenuation has played a vital role in reducing its strength. Stress wave values of amplitude and energy emitted by the roller defect were scattered between corresponding levels of the inner and outer race. This was attributed to the position of roller rubbing at the time of data acquisition, for instance, a higher level of amplitude/energy was expected when the roller defect made contact/rubbed with the outer race. A signature of reduced amplitude/energy levels was expected as the roller defect rubbed with the cage, and an even more reduced strength of signature was emitted due to defect contact with the inner race. This mechanism explains the scatter of roller defect amplitude and energy values between the inner and outer race values. All the results discussed above were observed for both types of grease.

\subsection{Grease contamination}

Stress waves associated with simulating grease contamination generated the highest values of amplitude and energy. This was attributed to the crushing of debris particles at the working interfaces. Differences in individual values of amplitude/energy, or the scatter of values, were attributed to the unique transmission paths from the position of crush. For instance, crushing of debris trapped between a roller and the outer race would 
have greater values of amplitude/energy than that generated between the roller and the inner-race. This phenomenon was attributed to attenuation.

\subsection{Classification}

Whilst the results already presented clearly show that extracting amplitude/energy values from SW could help indicate bearing deterioration, a more robust system of classification was investigated. The reason for this was that bearings on-site/in-operation could have background noise levels that were comparable to amplitude/energy levels associated with our fault simulations, making fault identification impossible. Thus an alternative method was developed which involved a clustering technique that utilised the Auto-Regressive (AR) coefficients associated with each SW signature. This technique has been shown $(1,2)$ to represent the distinct shapes of SW's, particularly, when they are emitted from sources with varying transmission paths, as in this case.

Clustering of AR coefficients associated with background noise SW signatures resulted in two cluster groups, figures 12 and 13, however, the distances between these cluster groups was relatively small. The main mechanisms responsible for generating background/operational noise were, firstly, the rolling action between the rolling elements and the races. Secondly, the rubbing action between the rolling elements and the non-working surfaces, i.e., the clamping rings. It is probable that these mechanisms accounted for the two cluster groups. 
By comparing classifications of background noise against all four-fault simulations, it was evident that the AR cluster technique showed distinct source groupings, and, was applicable to both grease types. In the majority of cases, there was a clear distinction between the background noise and fault, evident by the two main cluster groups, see figures 14 to 21 . However, in some instances three cluster groups were evident, though, the clustering of background noise still remained distinct from the other two clusters. These two clusters were attributed to changing characteristics of the defect with time, i.e., the defect might become smooth. It is thus probable that the change in defect characteristics resulted in an emission of distinct shape. In addition, the distinct manner that each roller approached the defect on the outer- and inner-races, and, the movement of the seeded defects on the roller could also contribute to slight changes in signature shape, thus contributing to such clustering results.

The classification of all defect simulation signatures with background noise, exclusive of grease contamination, resulted in well-defined clusters, see figures 22 to 27 . These clusters showed that the source of fault, and unique transmission paths, could be clearly distinguished. However, on the inclusion of grease contamination SW signatures to the above, the cluster results proved inconclusive. This was not unexpected, as signatures from grease contamination could have been triggered from any part of the bearing component, thus the grease contamination signatures would cluster to any one of the other seeded defect signatures. 
Given the scenario of an operational bearing with a fault, it is probable that SW signatures measured could contain background noise that was of similar amplitude/energy levels as the fault signature, consequently, we would be unable to differentiate the signatures by observing amplitude and energy values. However, because operational background noise is random in nature $(1,2)$, the shape of its signatures will also be random. The shape of SW signatures associated with the fault, in this instance and for a short period of time, would generally be of similar pattern. Thus, if clustering of the AR coefficients associated with all $\mathrm{SW}$ signatures yielded distinct group clusters, this would be evident of early signs of deterioration. If no distinct groups were evident, the bearing would be passed as defect free, as clustering of AR coefficients associated with random shaped signatures (background noise) will result in no clearly defined groups.

\section{Conclusion}

Investigations into the application of the stress wave technique to condition monitoring of slow-speed rotating element bearings have proven extremely successful. The uniqueness of the transmission path for the various fault conditions can be utilised to provide early fault diagnosis.

Results of the seeded mechanical faults on the test-rig showed that stress waves generated from rubbing of mating components were of complex pattern, indicative of their different transmission paths. Simulation of surface defects suggested that very early stages of surface defect (EDM simulation) may go undetected until such a time that the defects has 'matured' (spark eroding simulation) to a critical level of surface distortion. 
Classification of stress wave signatures from the test-rig showed that the Auto-Regressive (AR) coefficients associated with each stress wave provided an efficient and effective parameter for diagnosis. This particular technique has its strength in the ability to represent the shape of a stress wave by a few AR coefficients.

\section{References}

1. Mba, D., Bannister, R.H., and Findlay, G.E. 1999 Condition monitoring of low-speed rotating machinery using stress waves: Part I. Proceedings of the Instn Mech Engrs, pp 153-170, Vol. 213, Part E.

2. Mba, D., Bannister, R.H., and Findlay, G.E. 1999 Condition monitoring of low-speed rotating machinery using stress waves: Part II. Proceedings of the Instn Mech Engrs, pp 171-185, Vol. 213, Part E.

3. Mba, D., Bannister, R.H., and Findlay, G.E. 1999 Mechanical redesign of the rotating biological contactor. Part 1. Water Research, pp 3679-3688, Vol. 33, No. 18.

4. Mathew, J. and Alfredson, R.J. 1984 The condition monitoring of rolling element bearings using vibration analysis. Journal of Vibration, Acoustic, Stress and Reliability Design, Transactions of ASME, pp 447-453, Vol. 106.

5. McFadden, P. D. 1990 Condition monitoring of rolling element bearings by vibration analysis. Proceedings of the Instn Mech Engrs seminar on machine condition monitoring, pp 49-53. 
6. Ractliffe, G. A. 1990 Condition monitoring of rolling element bearings using enveloping technique. Proceedings of the Instn Mech Engrs seminar on machine condition monitoring, pp 55-65.

7. Harker, R. G. and Sandy, J. L. 1989 Rolling element bearing monitoring and diagnostics techniques. Transactions of the ASME, Journal of Engineering for Gas Turbines and Power, pp 251-256, Vol. 111.

8. Bannister, R. H. 1985 A review of rolling element bearing monitoring techniques. Instn Mech Engrs conference on condition monitoring of machinery and plant. pp $11-24$.

9. Setford, G. A. W. 1992 Bearings-condition monitoring, condition measurement and condition control. 4th international Conference on Profitable Condition Monitoring, bH ${ }^{\mathrm{r}}$ Group Ltd., pp 231-240, 8-10 Dec., Stratford-upon-Avon, UK.

10. Berry, J. E., 1992 Required vibration analysis techniques and instrumentation on low speed machines ( particularly 30 to 300 RPM machinery ), Technical Associates of Charlotte Inc.,Advanced Vibration Diagnostic and Reduction Techniques.

11. Canada, R.G., and Robinson, J.C., 1995 Vibration measurements on slow speed machinery. Predictive Maintenance Technology National Conference (P/PM Technology), pp 33-37, Vol. 8, no. 6. Indianapolis, Indiana.

12. Murphy, T.J., 1992 The development of a data collector for low-speed machinery. 4th international Conference on Profitable Condition Monitoring, $\mathrm{bH}^{\mathrm{r}}$ Group Ltd., pp 251-258, 8-10 Dec., Stratford-upon-Avon, UK.

13. Robinson, J.C, Canada, R.G., and Piety, R.G. 1996 Vibration Monitoring on Slow speed Machinery: New Methodologies covering Machinery from 0.5 to 600rpm. 
Proc. 5th International Conference on Profitable Condition Monitoring - Fluids and Machinery Performance Monitoring, pp 169-182, $\mathrm{bH}^{\mathrm{r}}$ Group Ltd., Publication 22, Harrogate, UK.

14. Kuboyama, K., Development of Low Speed Bearing Diagnosis Technique, NKK Fukuyama Works, Fukuyama City, Hiroshima, Japan.

15. Sato, I. 1990 Rotating machinery diagnosis with acoustic emission techniques, Electrical engineering in Japan, pp 115-127, Vol. 110, No. 2.

16. McFadden, P. D., and Smith, J. D. 1983 Acoustic emission tranducers for the vibration monitoring of bearings at low speeds, Report no. CUED/C-Mech/TR29.

17. Smith, J.D. 1982 Vibration monitoring of bearings at low speeds, Tribiology International, pp 139-144.

18. Zabihi, A., Swarnamani, S. and Prabhu, B.S. 1991, Fault diagnosis of roller bearing through mechanical signature analysis, Modelling, Simulation and Control, Vol 40, No 1, pp 53-64

19. Su, Y-T, Sheen, Y-T and Lin, M-H 1992, Signature analysis of roller bearing vibrations: lubrication effects, Proceedings of the ImechE, Part C, Journal of Mechanical Engineering Science, Vol 206, pp 193-202

20. Cheng, W., Cheng, H.S and Ai, X. 1993, Surface crack initiation under contact fatigue: experimental observation and contact analysis, Journal of Tribology, Vol 115, pp 658-665.

21. Li, C.J. and Li, S.Y. 1995, Acoustic emission analysis for bearing condition monitoring, Wear, Vol 185, pp 67-74. 
22. Mathew, J., Szczepanik, A., Kuhnell, B.T., and Stecki, J.S. 1987, Incipient damage detection in low speed bearings using the demodulation resonance analysis technique, Proceedings of the International Tribology Conference 1987, The Institution of Engineers Australia, Melbourne, Australia, pp 366-369

23. Tan, C.C. 1990, Application of acoustic emission to the detection of bearing failures", Proceedings of the International Tribology Conference 1990, The Institution of Engineers Australia, Brisbane, Australia, pp 110-114

24. Tandon, N. and Nakra, B.C. 1990, Defect detection of rolling element bearings by acoustic emission method, Journal of Acoustic Emission, Vol. 9, No. 1, pp 25-28.

25. Martin, K.F. and Thorpe, P. 1992, Normalised spectra in monitoring of rolling bearing elements, Wear, Vol 159, pp 67-77.

26. Kay, S.M, and Marple, S.L Jr. 1981 Spectrum analysis - A modern perspective. Proceedings of the IEEE, pp 1380-1419, Vol. 69, No. 11.

27. Makhoul, J. 1975 Linear prediction: A tutorial review. In Proc. Of the IEEE, PP 561580, Vol. 63, No. 4.

28. Haykin, S. 1984 Introduction to adaptive filters. Macmillan Publishing Company, New York. ISBN 0 - 02 - 949460 - 5.

29. Everitt, B. 1974 Cluster analysis. Published on behalf of the Social Science Research Council by Heinemann Educational Books New York: Halsted Press. ISBN 0435 822977.

30. Green, A. P. 1955, Friction between unlubricated metals: a theoretical analysis of the junction model. In Proc. Of the Royal Society of London, A, pp 191-204, Vol. 228. 